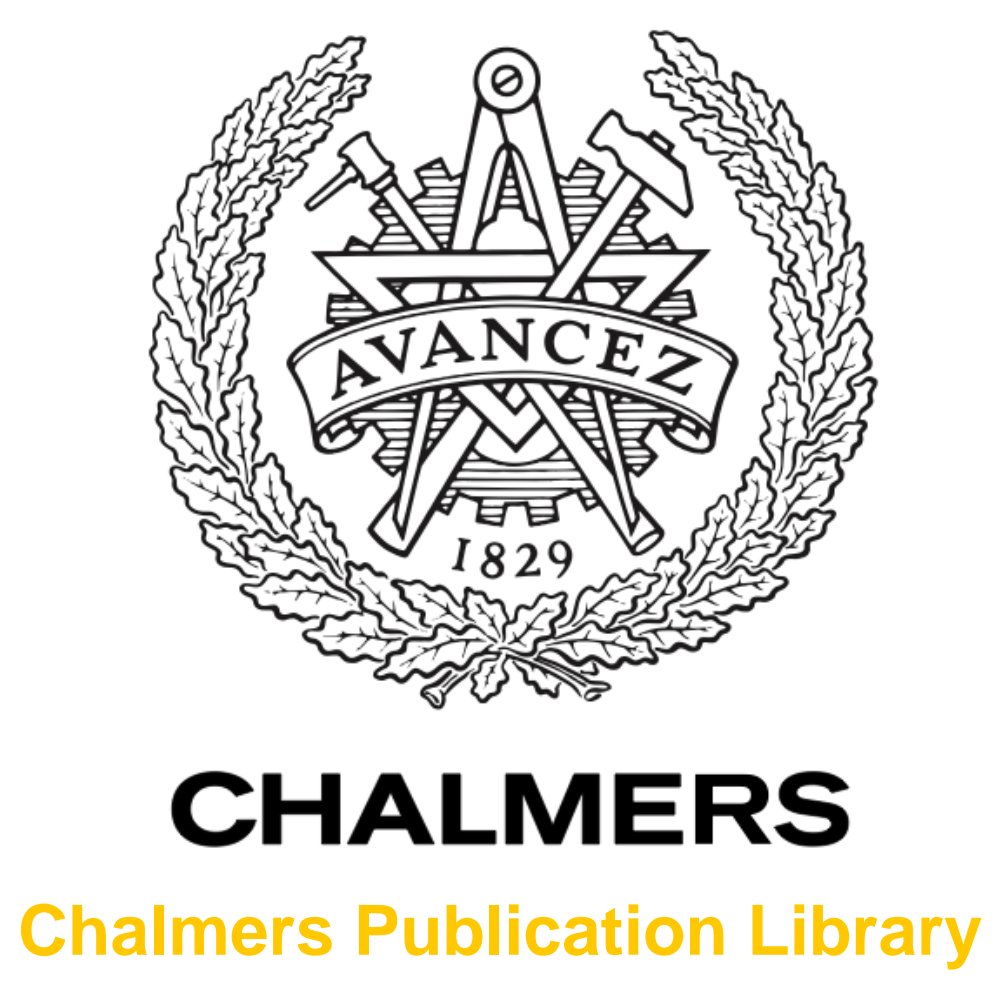

\title{
Value chains for integrated production of liquefied bio-SNG at sawmill sites - Techno-economic and carbon footprint evaluation
}

This document has been downloaded from Chalmers Publication Library (CPL). It is the author's version of a work that was accepted for publication in:

Applied Energy (ISSN: 03062619)

Citation for the published paper:

Ahlström, J. ; Pettersson, K. ; Wetterlund, E. et al. (2017) "Value chains for integrated production of liquefied bio-SNG at sawmill sites - Techno-economic and carbon footprint evaluation". Applied Energy, vol. 206 pp. 1590-1608.

http://dx.doi.org/10.1016/j.apenergy.2017.09.104

Downloaded from: http://publications.lib.chalmers.se/publication/253919

Notice: Changes introduced as a result of publishing processes such as copy-editing and formatting may not be reflected in this document. For a definitive version of this work, please refer to the published source. Please note that access to the published version might require a subscription. 


\title{
Value chains for integrated production of liquefied bio-SNG at sawmill sites - techno-economic and carbon footprint evaluation
}

\author{
Johan M. Ahlström ${ }^{*}$,a, Karin Pettersson ${ }^{\mathrm{a}, \mathrm{b}}$, Elisabeth Wetterlund ${ }^{\mathrm{c}}$, Simon Harvey ${ }^{\mathrm{a}}$ \\ ${ }^{a}$ Chalmers University of Technology, Dep. of Space, Earth and Environment, Div. of Energy Technology, SE-412 96 \\ Gothenburg, Sweden \\ ${ }^{\mathrm{b}}$ RISE Research Institute of Sweden, Eklandagatan 86, SE-412 61 Gothenburg, Sweden \\ ${ }^{\mathrm{c}}$ Energy Engineering, Division of Energy Science, Luleå University of Technology, SE-971 87 Luleå, Sweden
}

\begin{abstract}
Industry's increasing demand for liquefied natural gas could be met in the future by liquefied methane produced from biomass feedstock (LBG - liquefied biogas). This study presents results from an investigation of value chains for integrated production of LBG at a generic sawmill site, based on gasification of sawmill waste streams and forest residues. The objective was to investigate the cost for, as well as the carbon footprint reduction associated with, production and use of LBG as a fuel. Five different LBG plant sizes were investigated in combination with three different sawmill sizes. The resulting cases differ regarding biomass feedstock composition, biomass transportation distances, LBG plant sizes, how efficiently the excess heat from the LBG plant is used, and LBG distribution distances. Pinch technology was used to quantify the heat integration opportunities and to design the process steam network. The results show that efficient use of energy within the integrated process has the largest impact on the performance of the value chain in terms of carbon footprint. The fuel production cost are mainly determined by the investment cost of the plant, as well as feedstock transportation costs, which mainly affects larger plants. Production costs are shown to range from 68 to $156 \mathrm{EUR} / \mathrm{MWh}_{\text {fuel }}$ and the carbon footprint ranges from $175-250 \mathrm{~kg} \mathrm{GHG}$-eq $/ \mathrm{MWh}_{\text {net biomass }}$ assuming that the product is used to substitute fossil LNG fuel. The results indicate that process integration of an indirect biomass gasifier for LBG production is an effective way for a sawmill to utilize its by-products. Integration of this type of biorefinery can be done in such a way that the plant can still cover its heating needs whilst expanding its product portfolio in a competitive way, both from a carbon footprint and cost perspective. The results also indicate that the gains associated with efficient heat integration are important to achieve an efficient value chain.
\end{abstract}

Keywords: Liquefied bio-SNG; Process integration; Sawmill; Gasification; Value chain; System analysis.

\section{Nomenclature}
$\mathrm{CHP}$
CRF
DME
DS
FR
GCC
GWP
GHG
HDV
HRSC
LBG
LHV
NG
Odt
RME
SNG
TPC
WC
WtW

\author{
Combined heat and power \\ Capital recovery factor \\ Dimethyl ether \\ Dry substance \\ Forest residues \\ Grand composite curve \\ Global warming potential \\ Greenhouse gas \\ Heavy duty vehicle \\ Heat recovering steam cycle \\ Liquefied biogas \\ Lower heating value \\ Natural gas \\ oven dried tonne (metric) \\ Rape methyl ether \\ Synthetic natural gas \\ Total plant cost \\ Wood chips \\ Well-to-Wheel
}




\section{Introduction}

Many countries have established targets to achieve a transition from fossil to renewable fuels within the transport sector. Sweden has adopted a target of a fossil-independent transport sector by 2030 [1]. Demand for biofuels produced from lignocellulosic feedstock is thus projected to increase significantly in the future [1].

Extensive work has been put into estimating the carbon footprint and economic performance of producing synthetic natural gas (SNG) from biomass feedstock (hereafter referred to as bio-SNG). A process design and evaluation study of a direct, steam blown, biomass gasifier for bio-SNG production was performed by Gröbl et al [2]. The study focused on small-scale gasifiers for decentralized bio-SNG production and indicated that a total process cold gas efficiency of $68 \%$ could be achieved if wood pellets (19.55\% moisture content by weight) are used as feedstock. Through sensitivity analysis, it was concluded that gasification temperature and air pre-heating temperature have a large impact on the performance of the gasifier. Gassner and Maréchal [3] performed a thermo-economic optimization of a polygeneration plant producing bio-SNG, power and heat from gasified lignocellulosic biomass. Their results indicate that a systematically optimized process flowsheet could achieve conversion efficiencies of $66-75 \%$ from wood ( $50 \%$ m.c. by weight) to bio-SNG (LHV basis), for concepts that include simultaneous production of heat and electricity. Alamia et al. [4] performed a well-to-wheel study of production of bio-SNG for use as fuel for heavy duty vehicles within the transport sector of the European Union. Their results indicate a GHG emissions reduction potential of up to $67 \%$, depending on engine type, compared with fossil diesel. The study was based on data from the GoBiGas demonstration bio-SNG plant in Gothenburg, Sweden. GoBiGas is the world's largest biomass gasification plant with a full downstream synthesis process and has a production capacity of 20 MW bio-SNG. The plant uses wood pellets with an $8 \%$ moist content (by weight) as feedstock. The total biomass-to-methane efficiency of the plant is $65 \%$ (LHV basis) and the overall system energy efficiency, which includes delivery of excess heat to a district heating network, is above 90\% (LHV basis) [5].

Pettersson et al. [6] investigated opportunities for future cost-efficient production of biofuels in Sweden, considering different possible plant locations. The results indicate that bio-SNG, especially integrated production at sawmill sites, is an interesting fuel due to high conversion efficiency and good opportunities for both heat and feedstock integration with the host plant. The energy, greenhouse gas (GHG) and cost performance of value chains for production of bio-SNG as a vehicle fuel were evaluated in an well-to-wheel analysis by Börjesson et al. [7]. Their results indicate that using renewable methane as a vehicle fuel result in reduction of WTW GHG emissions of $80 \%$ or higher compared to vehicles operated with fossil diesel or gasoline. Furthermore, the WTW costs for bio-SNG are similar to those of comparable fossil fuels, applying current (2016) prices for fossil fuels.

Börjesson et al. [8] and Ekbom et al. [9] investigated the perspectives for bio-SNG production from gasified biomass in terms of reduction of GHG emissions (7.5-8.5 tonnes $\mathrm{CO}_{2-\text { eq/ }}$ ha land use) and production costs (5.5-7 SEK/I of gasoline equivalent). Both studies concluded that bio-SNG is an attractive fuel compared to other biofuel alternatives, mainly due to low production costs. However, both studies emphasize the potential risk for expensive distribution costs due to low energy density of the fuel. Calderón et al. [10] investigated supply chains for bio-SNG production in the United Kingdom. Their results indicate that the UK could cover $21.4 \%$ of its total gas demand using domestic biomass feedstock resources, considering a planning horizon of 20 years. The results indicate operating costs of bio-SNG production facilities as the main cost in the supply chain, followed by the required investments new bio-SNG production sites.

There are also a number of published studies investigating process integration opportunities for gasificationbased biofuel production. Previous studies of gasification-based biofuel production, comparing process integrated facilities to stand-alone production, suggest that co-locating and integrating biorefineries with existing industrial plants is beneficial from an energy perspective and results in lower fuel production costs. Heyne et al. [11] showed how production of electricity as a by-product from a bio-SNG plant can be increased by a factor 2.5-10 if the plant is integrated with a CHP plant, depending on the type of biomass dryer that is used. Andersson et al. [12] showed how the total energy efficiency of a biorefinery plant based on an entrained flow gasifier can be increased by 7 percentage points if the unit is heat integrated with an existing chemical pulp and paper mill. Aziz et al. [13] investigated process integration of empty fruit bunch (a by-product from palm oil production) drying with gasification and combined cycle systems. The idea is to use excess heat from a combined cycle to dry the fruit bunch gasifier feedstock. The gasifier syngas product is then cleaned and used as fuel in the combined cycle. The results show that integrating the dryer reduces the primary energy usage of the drying plant by $30 \%$ compared to stand-alone drying. The plant's electric power generation efficiency reaches $44 \%$ for a gasification temperature of $1000^{\circ} \mathrm{C}$. These increases in efficiency are primarily due to co-location of the plants which allows heat to be cascaded between the processes, thus decreasing the need for primary energy.

Bio-SNG production processes perform comparably well from both an economic and a GHG emissions reduction perspective because they have high biomass-to-SNG conversion efficiencies and there are significant amounts of excess heat available at high temperature from the SNG process which can be harnessed by heat 
integrating a steam cycle with the process. The steam can be used to cover the process heating needs, while cogenerating electricity, resulting in an increased combined energy output in relation to the energy input in biomass. Use of bio-SNG as an energy carrier has the disadvantage that it has a low energy density compared to liquid energy carriers and DME (dimethyl ether). This makes distribution of the product relatively inefficient and expensive for all cases where it cannot be transported in pipelines. It also makes SNG less attractive as a fuel, since the volume of the fuel storage needs to be significantly larger than for more energy dense fuels, unless very high pressure tanks are used. An alternative way to increase the energy density of the product is to liquefy the bio-SNG (liquefied bio-SNG is hereafter denoted LBG - liquefied biogas). The energy density of LBG is then approximately 600 times higher than that of bio-SNG, which results in significantly decreased distribution costs [14].

Kumar et al. [15] state that the market for fossil LNG is expected to increase during coming years. High energy density and efficient low-cost production are presented as key reasons to expect that LNG could become a significant fuel for heavy duty vehicles in the future. Due to the positive fuel characteristics of liquefied natural gas (LNG), there are a number of ongoing political initiatives to increase the demand for this fuel. The EU-cofinanced Northern European LNG Infrastructure project was initiated in 2015. The project aims at developing pathways for an expansion of the LNG infrastructure required to implement LNG as a ship bunker fuel in the Baltic Sea [16]. An increased demand for LNG as a fuel can also be observed from shipping companies and ship manufacturers, for instance the Nordic cruise company Viking Line operates a number of LNG propelled ferries on its regular Baltic Sea routes. Within the trucking industry, a development towards LNG as a fuel is also emerging. The EU-financed "LNG blue corridors" project presents suggestions for road corridors with evenly distributed LNG-fueling stations that could enable a broad market implementation of heavy duty vehicles (HDV) running on LNG in Europe [17].

Even though natural gas is a fossil fuel, it has lower life cycle combustion GHG emissions per unit of energy compared to fossil diesel or gasoline, assuming a well-maintained gas grid with low leakage. Additionally, if market development towards increased use of fossil LNG occurs, LBG could gradually be mixed with LNG and eventually replace it, thus allowing for phase-out of fossil fuels without requiring a shift in end-use technology and distribution infrastructure.

A number of previous studies of forest biomass-based fuel production have focused on integration opportunities with different host industry types (e.g. $[18,19])$. This paper focuses on integration with sawmills (generic Nordic sawmills). Several factors motivate the selection of sawmills as host sites for integrated bio-SNG production: (i) sawdust, bark and wood chips are by-products at all sawmills, and could be used as feedstock for an LBG plant; (ii) the sawmill's internal heat demand (mainly for drying of the sawn wood) can be covered by excess heat from the LBG plant; (iii) infrastructure for feedstock handling already exists at a sawmill, thus allowing for lower investment costs. Additionally, handling large quantities of biomass residues is a complex issue, thus the know-how and experience that exist at sawmills is a major asset from an integration perspective. Sweden is used as a case study, but the results are relevant for other countries with significant forest resources and sawmill facilities.

Sawmill-integrated bio-SNG production has been investigated previously by Mesfun et al. [20], who used a process integration approach to assess the potential for increasing the profit margin of sawmill by-products by using them for production of bio-SNG or production of electricity in an integrated gasification combined cycle. Pettersson et al. [6] used a geographically explicit approach to evaluate different forest industry integrated biofuel production options. Their results indicate that integration of a facility for production of bio-SNG at a sawmill site is attractive for scenarios where electricity prices and transportation costs of feedstock are high.

Literature thus includes a number of studies that have investigated process design and optimization of gasification processes for bio-SNG production. Likewise, there are a number of papers presenting system studies of large-scale implementation of bio-SNG as a fuel. However, even though integration gasification-based production of bio-SNG fuel at a sawmill site has been investigated in a number of existing studies, research is lacking on the value chain performance of such a concept, as well as a thorough investigation of the possible benefits of liquefying the bio-SNG fuel product. Similarly, no previous work has been found that investigates how the selected size of a LBG gasification process in relation to the sawmill size affects the economic and carbon footprint performance of the entire value chain. If considering large scale implementation of biofuel production integrated with existing industrial plants, it is important to estimate the impact of process integration opportunities on costs and emissions, but also to investigate how the impact of process integration opportunities relates to that of other key characteristics of the value chain, such as transportation distance. It then becomes possible to study whether the process integration opportunities enhance the economic performance of the integrated biorefinery, or if the advantages of integrating processes to better utilize heat and lessen transportation distances of feedstock and product, are small compared to the inherent economies of scale that can be achieved by large biofuel production plants, regardless of whether they are process integrated with other process plants or not. This work 
combines the process integration approach with a full value chain evaluation for integration of LBG production at a sawmill site, thus achieving the detailed value chain overview required for evaluation of a biorefinery process concept that has not been evaluated to a similar extent before. The results provide insights about the value chain steps that have the largest impact on the overall production cost and carbon footprint, and how the value chain performance is affected by the relative size of the LBG process.

The objectives of this paper are to (1) present production cost and carbon footprint results for the entire value chain of an integrated thermos-chemical biorefinery process producing bio-SNG from biomass feedstock at a sawmill site, with additional liquefaction of the product to LBG; (2) identify the sections of the value chains that have the largest impact on the integrated plant's production cost and carbon footprint; and (3) identify suitable sizing criteria for LBG production plants integrated with sawmills.

\section{Methodological framework}

An overview of the studied system is provided in Section 2.1 and the evaluation methodology is presented in Section 2.2. Detailed descriptions of methods and assumptions are found in Section 3.

\subsection{Studied system}

Figure 1 shows the reference system value chain together with the studied LBG system, including the relevant system boundaries considered in this work. The results presented focus on the relative differences between key performance indicators for the LBG production process integrated with a sawmill and a reference system consisting of the same generic sawmill (as defined in ref [21]) without LBG production. 


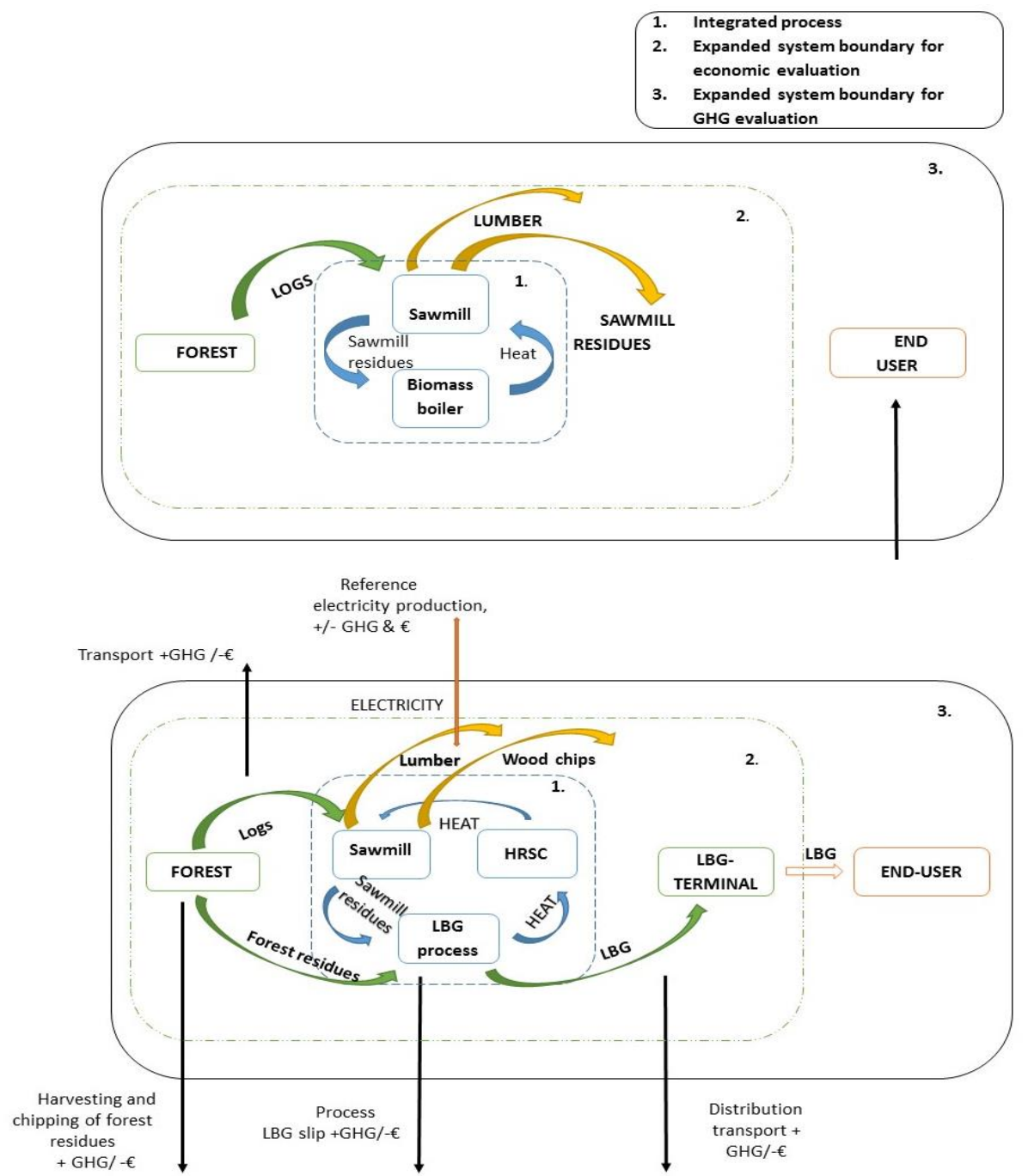

Figure 1 Value chain overview including relevant system boundaries for system analysis. a) reference stand-alone sawmill, b) integrated sawmill-LBG process

The inner dashed square, marked 1 in Figure $1 \mathrm{~b}$ ), corresponds to the boundary of the system consisting of a sawmill heat integrated with an LBG process through a heat recovery steam cycle (HRSC). The integrated process differs from the sawmill in the reference system (Figure $1 \mathrm{a})$ ) where the heating needs are satisfied through combusting a fraction of the available sawmill residues in a biomass boiler, i.e. in the reference system the sawmill residues not required for heat generation are exported, instead of being used as feedstock for LBG production. In this study, the only emissions considered are emissions of greenhouse gases. Important environmental impacts such as e.g. eutrophication, biodiversity, particulate emissions, water use etc. are not considered. The reason for this choice is that the focus of the paper is on exploring the impact of process integration opportunities on value chain performance, which mainly affects the energy balance of the considered system, and thereby the GHG emissions. To quantify the potential for reducing the system carbon footprint, it is important to include the substitution of fossil fuels. Therefore, the carbon footprint evaluation adopts a well-towheel perspective and includes the end user (the system boundary marked by the solid line labelled 3 in Figure 1b)). Furthermore, the different cases studied (as discussed further in Section 3.1) correspond to different net usage of biomass feedstock. Therefore, this study does not include an assessment of the possible profitability of LBG production, but instead focuses on the comparison of fuel production costs (from forest to LBG terminal, the system boundary marked by the dashed and dotted line, labelled 2 in Figure 1 b)) of the studied value chain cases. The forest residues used for LBG production are assumed to be left in the forest if not used as feedstock. The impact of soil carbon depletion is not considered in this study and neither are methane emissions resulting from decay of logging residues left in the forest. For waste biomass, such as forest residues, soil carbon dynamics can have a significant impact. When logging residues are removed from the forest, the soil carbon stock decreases more than if the residues were left in the forest to decompose. The effect of decreased soil carbon is time dependent. In a short time frame, it has a large effect on GHG savings, but using a longer time perspective 
(20 years) a major part of the soil carbon has been emitted to the atmosphere as $\mathrm{CO}_{2}[22,23]$. All indirect land use effects are also left outside the scope of this study.

In general, a time perspective of 2030 is applied for the analysis. Given the lack of published studies estimating emissions and cost of future heavy transport and forest logging operations, these parameters were assumed to be equal to current (2017) values.

\section{$2.2 \quad$ Framework}

Three different sawmill sizes representative for the Nordic countries were considered. For each sawmill size, five different plant sizing criteria were considered for the LBG process in relation to the corresponding sawmill size, thus resulting in a total of fifteen cases. Descriptions of the cases and their corresponding sizing parameters are presented in Section 3.1. The different cases differ significantly with respect to total biomass mixes used, biomass transportation distances, LBG plant sizes, efficiency in the use of excess heat and LBG distribution distances, which makes it possible to identify the parameters that have the largest impact on the value chain production cost and the carbon footprint.

The evaluation was performed according to an energy system assessment approach which has been applied for industrial energy processes in previous studies, e.g. Holmgren et al. [24]. The working procedure applied in this article includes the following steps, which are described more in detail in Section 3:

1. Mapping of process data and collection of stream data for energy flows. All process stream data (type, mass flow and temperature) is collected for the considered LBG process and sawmill, together with data for the electricity balances. All stream and electricity data are assumed to scale linearly with production capacity.

2. Energy targeting calculations. Pinch analysis is applied to construct the grand composite curves (GCC) for the LBG and sawmill processes. Thereafter, a foreground/background analysis is performed including an integrated heat recovery steam cycle (HRSC). In this way, the possibility of producing electricity as a by-product from the integrated process is quantified. The steam cycle is configured for maximum electricity production using a linear programming optimization tool.

3. Feedstock collection and product distribution. For cases in which additional feedstock is required for the sawmill, the necessary collection area for forest residues is estimated. The distribution distance for the finished product is estimated by mapping planned LNG terminals and sawmills in Sweden.

4. Energy balance of the value chain. Results from the energy targeting step are used to establish the energy balance of the plant and energy usage related to feedstock collection and product distribution is estimated.

5. Carbon footprint. The net greenhouse gas emissions, reported as $\mathrm{CO}_{2}$ equivalents (GWP_100 basis) are reported per net amount of used biomass; the produced LBG fuel is assumed to replace fossil LNG.

Methane slip from both the production and the distribution of LBG are considered. A base-load marginal electricity generation technology is specified, to account for emissions associated with net import/export of electricity to/from the studied system.

6. Economic performance. Evaluated on the basis of Fuel Production Cost (FPC). The investment cost for the process is annualized by applying the annuity method, using a discount rate of $8 \%$ and an economic lifetime of 20 years.

7. Sensitivity analyses. To highlight the influence of different parameters on the results, sensitivity analyses are performed with focus on the economic performance.

\section{Methods, assumptions and input data}

Section 3.1 describes the integrated biorefinery cases considered in this study. Process data is presented in Section 3.2. All data and assumptions related to transportation are presented in Section 3.4. Assumptions and data related to process integration and the steam network are presented in Section 3.3 and data for the carbon footprint calculations in Section 3.5. In Section 3.6 the economic calculations and related data and assumptions are presented.

\subsection{Plant sizing for LBG production}

This study differentiates between sawmill residues, consisting of by-products from the sawmill, and forest residues, consisting of branches and tops from forest harvesting. Each sawmill size is evaluated with respect to heat and feedstock integration opportunities with the gasification-based LBG production process. The sawmill 
powerhouse is only assumed to include a steam turbine condensing unit for the cases where there is more steam produced than required for process heating purposes at the integrated site, and where the investment is deemed economically feasible in relation to the resulting additional power production. The LBG plant is assumed to be sized according to five possible limiting factors:

- $\quad$ Case 1 - Available sawmill residues. In this case, the LBG plant is sized to use all available sawmill residues (sawdust, wood chips and bark) as feedstock. Thus, this case produces as much LBG as possible without importing any extra feedstock to the plant site.

- $\quad$ Case 2 - Available sawmill residues excluding wood chips. In this case, the LBG plant is sized to use all available sawmill residues (bark and sawdust) but not the wood chips, which are instead assumed to be sold as feedstock for pulp production. In this case, there is not enough excess heat from the gasifier to cover the heat demand of the sawmill. Therefore a fraction of the available sawmill residues are combusted directly in a boiler, producing heat, which is used for steam production in the integrated HRSC. The fraction of the residues fed to the boiler is determined so as to maximize electricity production without the need to invest in a condensing steam turbine unit in the HRSC powerhouse.

- $\quad$ Case 3 - Forest residues uptake area. The required uptake area for timber logs to the sawmill is estimated. It is assumed that $80 \%$ of all available branches and tops within the same area are imported as feedstock to the LBG process.

- $\quad$ Case 4 - Sawmill heat demand. In this case, the LBG plant is sized according to the sawmill's heat demand. The feedstock supply rate to the LBG plant is determined based on the requirement that the excess heat released by the LBG plant is sufficient to satisfy the heat demand of the HRSC powerhouse assumed to consist of a back-pressure steam unit (without a condensing unit) that is designed for the full boiler steam flow. The fuel requirements are such that additional forest residues must be purchased to satisfy the feedstock requirements of the LBG plant.

- $\quad$ Case 5 - Large scale. In this case, a fixed production of $500 \mathrm{MW}$ LBG is considered. $500 \mathrm{MW}$ represents a scale of production with a feedstock intake similar to that of a large pulp mill [25]. For this case, the electricity production through the HRSC is maximized.

Figure 2 provides an overview of the five LBG cases corresponding to different limiting factors for plant sizing.

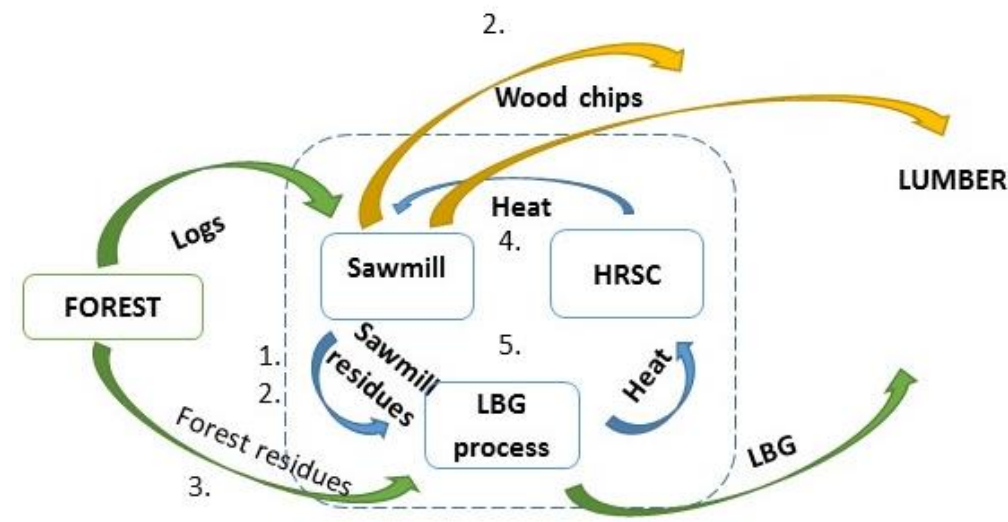

Figure 2. Overview of possible limiting factors for $L B G$ plant sizing.

\subsection{Collection of process stream data}

Start and target temperatures and energy flows were collected for all process stream heating and cooling operations. The data was collected from previous studies. These studies are presented in the following sections, together with descriptions of the corresponding processes.

\subsubsection{Sawmill process}

Three different sawmill sizes were considered; $50000 \mathrm{~m}^{3}, 250000 \mathrm{~m}^{3}$ and $500000 \mathrm{~m}^{3}$ of sawn dry wood per year, representing typical sizes for small, average, and large mills in Sweden. Sawmill data is based on Andersson \& Toffolo [21] and is presented in Table 1. The data describes key material stream characteristics and heating needs of a generic Nordic sawmill. The sawmill's electricity demand is not considered as it will be the same for the reference mill and for the mill integrated with the LBG plant and hence will not affect the results.

Table 1. Sawmill characteristics from Andersson \& Toffolo, per $\mathrm{kg}$ of sawn lumber [21].

\begin{tabular}{lll} 
Timber logs & 2.12 & $\mathrm{~kg}$ dry \\
Heating need for drying of wood & 2645 & $\mathrm{~kJ}, 75^{\circ} \mathrm{C}$ \\
Heating need for space heating & 353 & $\mathrm{~kJ}, 30^{\circ} \mathrm{C}$ \\
\hline
\end{tabular}




\begin{tabular}{lll}
\hline Lumber & 1 & kg dry \\
Residues & & \\
$\quad$ - Sawdust & 0.17 & kg dry \\
$\quad$ - Woodchips & 0.55 & kg dry \\
$\quad$ - Bark & 0.4 & kg dry \\
Moist content & $50 \%$ & Weight base \\
LHV & 8.59 & $\mathrm{MJ} / \mathrm{kg}$ \\
\hline
\end{tabular}

The data in Table 1 is presented per kg of dry sawn lumber product. It is assumed that the data from Table 1 can be scaled linearly for the three sawmill sizes. The heating needs for the sawmill result primarily from the heat needed to dry the sawn wood. Heating values were estimated based on data presented in [26]. The LHV for forest residues is dependent on their composition for which literature values vary substantially. The LHV value of forest residues is therefore assumed to be the same as that of the residues from the sawmill. For the reference case used for comparisons, it is assumed that an investment is made in a biomass heat only boiler with a thermal efficiency of $85 \%$ (LHV basis). The reference boiler is assumed to be a heat only boiler since this study assumes a comparison with a reference generic sawmill [21] and thereby the energy system is assumed to be designed according to standard practice for such operations. For increased efficiency, the reference case could also include an integrated steam cycle. This option was, however, considered to be beyond the scope of this study.

The boiler is assumed to use the same fuel composition as that specified in Andersson et al. [21]. In theory, bark fuel has the lowest economic value and should constitute $100 \%$ of the fuel for heat production, but this is not possible due to combustion related issues.

For Case 2, where wood chips are exported, the excess heat from the LBG process is not sufficient to cover the heating needs of the sawmill, therefore a fraction of the sawmill residues are assumed to be combusted in a boiler instead of being used as feedstock for the LBG plant. The boiler is assumed to have the same efficiency as the boiler used in the reference case (85\% LHV). However, for this case it is assumed that sawdust is used instead of wood chips as biomass boiler fuel. This enable the possibility to export all available wood chips. The LHV is assumed to be the same for both wood chips and sawdust. To enable the comparison, the reference boiler uses the same fuel mix in this case. The fuel composition for all boilers considered is presented in Table 2.

Table 2. Fuel feed to boiler in weight-\%.

\begin{tabular}{cc} 
Boiler & Fuel mix [weight-\%] \\
\hline Reference & $6 \%$ woodchips, 9\%sawdust, 85\% bark \\
Sawmill export case & $15 \%$ sawdust, 85\% bark \\
Reference Sawmill export & $15 \%$ sawdust, 85\% bark \\
\hline
\end{tabular}

\subsubsection{LBG process}

The process flowsheet is presented in Figure 3. The data used for estimating the energy balances of the bioSNG production unit in this study was extracted from simulations presented by Heyne [27]. Approximately $35 \%$ of the biomass residue stream from the sawmill is used as feedstock in the LBG process and consists of bark. This differs from the feedstock assumed in the simulations presented in ref. [19]. Experimental data and evaluation of gasification of bark or biomass feedstock with varying fractions of bark is not available for indirect gasifiers. Direct air-blown bark gasification has been implemented at pulp and paper industries since the 1980s ( see e.g. [28]). After discussions with experimental researchers, it was assumed that it is possible to use a feedstock consisting solely of bark in the gasifier [29].

The LBG process is assumed to adopt indirect gasification technology as demonstrated in the GoBiGas project (see e.g. [30]). Tar removal from the syngas is accomplished with a chemical looping reformer together with a cyclone. The methanation reaction occurs in an adiabatic two-step methanation unit, with intermediate separation of $\mathrm{CO}_{2}$. The reason for using an adiabatic methanation unit, rather than an isothermal unit, is that the adiabatic unit is commercially available. It was also shown by Heyne \& Harvey [31] that the impact of choice of methanation technology on overall performance for the entire system is negligible. The same study also showed that for adiabatic methanation, air drying of the biomass is more suitable from an efficiency perspective, compared to steam drying. Therefore an air dryer was assumed in this study, drying the biomass to a moisture content of $20 \%$ (weight basis) before it is fed into the gasifier. The $\mathrm{CO}_{2}$ removal step is assumed to adopt an amine-based solvent, in accordance with the investigation by Heyne and Harvey [32]. The bio-SNG plant achieves a biomass to LBG conversion efficiency of $69.4 \%$ (LHV basis) and has a specific electricity consumption of $0.115 \mathrm{MWh} / \mathrm{MWh}$ SNG. 


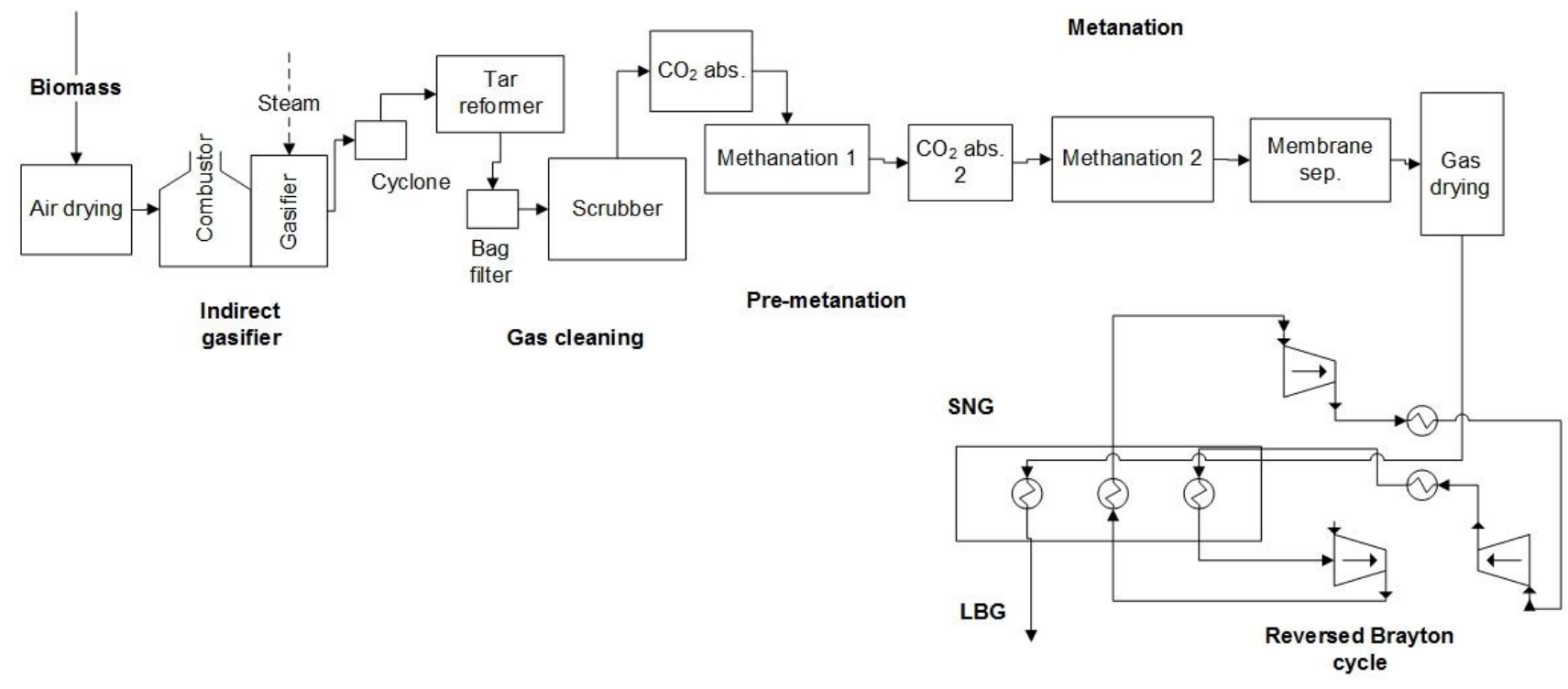

Figure 3: Process schematic of the LBG process. Developed based on [24].

The data for the liquefying unit condensing the bio-SNG to LBG is based on [33], in which a stand-alone liquefying unit was modelled. A reversed Brayton cycle operating at 40 bar is used to liquefy the gas. Two compressor stages with intercooling are assumed in order to decrease the compression power requirements. The electricity used per unit of LBG produced in the liquefying unit is adjusted to the inlet pressure as suggested by [34], resulting in a specific electricity demand of $0.034 \mathrm{MWh} / \mathrm{MWh}$ LBG.

\subsection{Heat integration of the sawmill and LBG plants}

There are large temperature differences both between hot and cold streams in the LBG process and between the heat sources in LBG process and the heat sinks in the sawmill. To increase the energy efficiency of the process, the heat flows are cascaded through an integrated HRSC. The steam is used for electricity production in a back-pressure steam turbine with extraction ports at the pressure levels required to cover the process steam demands. For the cases where the LBG process produces more heat than is needed in the sawmill, a condensing unit with a steam exhaust pressure level of 0.1 bar is included in the steam cycle, thus using the excess heat to produce electricity. Due to the thermodynamic characteristics of the steam cycle, and the physical constraints of droplet formation in the steam turbine, a re-heating step is included in the cases where a condensing unit is included in the steam cycle. This ensures that the fraction of the steam that expands from boiler pressure down to the condensing pressure is re-heated to the cycle maximum temperature at the pressure where the first droplets would have been formed, i.e. at saturated vapour conditions. A simplified overview of the steam system is presented in Figure 4.

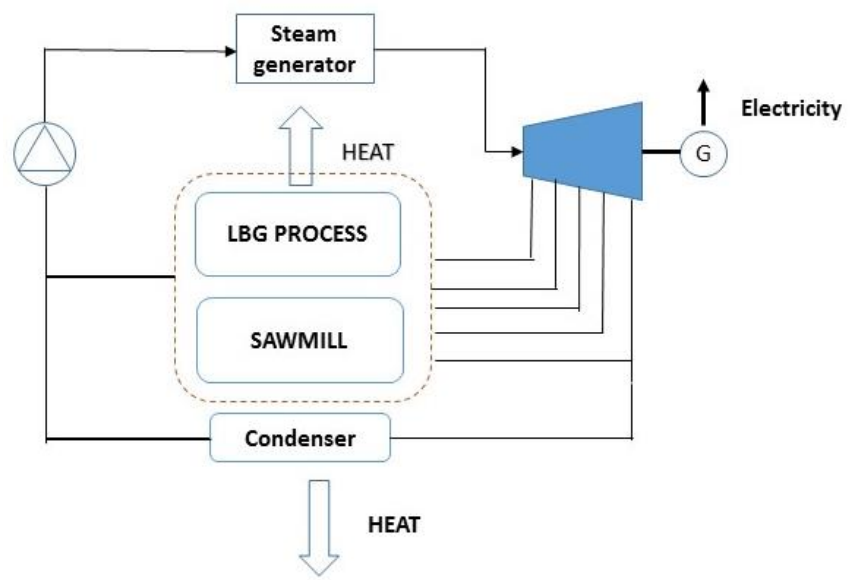

Figure 4. Simplified flowsheet showing how heat integration is achieved between the sawmill and the LBG process through a HRSC, the re-heater is not included for simplification of the figure. . 
To estimate the opportunities for heat integration within the LBG plant and between the LBG plant and the sawmill, pinch analysis is used. Pinch analysis (as described for example in Kemp [35]) provides a structured way for the user to determine the maximum level of heat recovery that can be achieved within the process, as well as the minimum hot and cold utility requirements. This is done by identifying all hot streams (streams that must be cooled from a given start temperature to a specified target temperature) and cold streams (streams that must be heated). Based on the known heating and cooling loads for these streams, as well as the minimum allowable temperature difference $\Delta T_{\text {min }}$ for heat exchanging between streams, it is then possible to calculate how heat cascades through the process from the highest temperature level down to the lowest temperature level. The resulting heat flow cascade through a process can be visualized in the grand composite curve (GCC), which can be used to investigate process utility options as well as opportunities for heat integrating different processes with each other. The method allows differentiated $\Delta T_{\min }$ values to be assumed for different stream types, as shown in Table 3 (the value listed is the individual stream contribution).

Table 3. Minimum temperature differences for different stream types.

\begin{tabular}{cc} 
Stream type & Individual $\Delta \mathrm{T}_{\min }$ stream contribution $\left[{ }^{\circ} \mathrm{C}\right]$ \\
\hline Water & 5 \\
Evaporation & 2.5 \\
Gas & 20 \\
Liquid streams & 10
\end{tabular}

For pinch analysis purposes, the sawmill can be represented as two thermal streams, which are both added to the thermal streams for the LBG process to construct the GCC of the combined process. The reversed Brayton cycle, used to condense the bio-SNG to LBG, operates at sub-ambient temperatures which excludes the possibility of heat integration with other process streams. Therefore it was not included in the pinch analysis. To assess the possible electricity production for each case, a linear optimization tool developed by Morandin et al. [36] was used. For each case, the tool is used to construct the foreground curve of a HRSC, for a back-pressure turbine with five extraction ports, in relation to the background GCC of the integrated sawmill-SNG-process. The objective of this approach is to simultaneously maximize the electricity production of the process and the LBG production. For detailed assumptions of the HRSC the reader is referred to Appendix. B Process and process simulation assumptions

\subsection{Feedstock transportation and LBG product distribution}

\subsubsection{Forest residues}

The study assumes a that 34.8 TWh/y of forest residues are available in the year 2030, as discussed by Wetterlund et al. [37]. Forest residues are assumed to consist of branches and tops, excluding stumps. The reason for excluding stumps is partly because the estimations for harvesting potentials vary substantially between sources, and partly because the environmental effects of removing stumps are hard to predict [38]. Calculations of the uptake area for forest residues are presented in Appendix A. Transportation calculations.

To calculate the transportation distance to the sawmill, a circular uptake area $(A)$ is assumed. Since transports will be from all distances within the circular area, an average transportation distance is estimated as $1 / \sqrt{2}$ times the uptake area radius. A dimensionless tortuosity factor $(T)$ of 1.4 is applied to take into account that road networks do not allow straight-line transportation, as suggested by [39]. The transportation distance, I, is thus calculated according to Equation 1:

$$
l=\frac{1}{\sqrt{2}} * \sqrt{\frac{A}{\pi}} * T
$$

The trucks used to transport the chipped forest residues to the LBG plant are assumed to run on standard low-sulphur Swedish road diesel MK1 mixed with $5 \%$ bio diesel (RME). Half of the transportation distance is operated with an empty truck, and a fraction of the transportation takes place on forest roads, which affects emissions as well as costs (see Sections 3.5 and 3.6) [40]. With data for transportation distance and truck capacity known, the number of required trucks can be calculated as well as the required energy usage, GHG emissions and costs for transportation of forest residues and for transportation of the LBG product [41]. The fuel consumption for the trucks is specified to $4.8 \mathrm{kWh}$ diesel $/ \mathrm{km}$. For a thorough review of all assumptions and calculations made, the reader is referred to Appendix A. Transportation calculations. 


\subsubsection{LBG distribution}

The LBG product is assumed to be transported to LNG terminals, which constitute the end points of the value chain. Existing as well as planned LNG terminals in, or close to, Sweden were mapped regarding location and LNG handling capacity, based on data from [16, 42]. Transport of produced LNG is assumed to be performed by heavy duty trucks using the same fuel as used for the transportation of forest residues. LNG terminals are considered as the end-point of the value chain in order to obtain an estimation of a representative distribution distance. If the product is used as fuel for trucks, it is more likely that it is distributed directly from the plant to fuelling stations. It is not possible to estimate an average distribution distance to fuelling stations in Sweden. However, this distance is likely to be shorter than the average distance to an LNG terminal and should therefore have a lower impact on the emissions and costs of the value chain.

The sawmills in Sweden were divided into three size classes following the classification used for the integration analysis (Section 2). The average transportation distances from each sawmill to the nearest LNG terminal were established using the ArcGIS mapping tool. Data for the sawmills, their location and capacities were taken mainly from [43] and verified with [44]. For this transportation it was also assumed that half of the distance is with an empty truck. The resulting distribution distances for LBG from plants at different sawmills are presented in Table 4 and are used for the GHG emissions and economic analyses.

Table 4. The average transportation distance to the nearest LNG terminal in Sweden, for the three sawmill sizes.

\begin{tabular}{cc} 
Sawmill size $\left(\mathrm{m}^{3}\right.$ sawn goods/yr $)$ & Distance $(\mathrm{km})$ \\
\hline 50000 & 202 \\
250000 & 207 \\
500000 & 163
\end{tabular}

The fuel consumption of the trucks was specified to $3.9 \mathrm{kWh}$ diesel $/ \mathrm{km}[7,45]$. For a thorough review of all assumptions and calculations made, the reader is referred to Appendix A. Transportation calculations.

\subsection{Estimation of carbon footprint}

To quantify the carbon footprint of the studied systems, the results are assessed in terms of carbon dioxide equivalents $\left(\mathrm{CO}_{2-\text { eq }}\right)$ per net amount of processed biomass in comparison to the reference system. The reason for quantifying the emissions per net amount of biomass is that this enables the reference use of biomass can be accounted for, giving a more accurate representation of the carbon footprint. A WTW perspective is applied for the carbon footprint calculations and all GHG emissions from harvesting of the biomass to the end-use of the fuel are included in the analysis. Data for the GWP of different emissions are taken from the International Panel on Climate Change fifth assessment report from 2013 which estimates the 100 year global warming potential in $\mathrm{kg}$ $\mathrm{CO}_{2 \text {-eq }} / \mathrm{kg}$.[46]. The GWP for methane is 34 , in relation to $\mathrm{CO}_{2}$ which has a GWP of 1 . To account for the GHG emissions associated with net import/export of electricity to/from the studied system, the marginal effect on grid electricity base load generation is considered. It is assumed that the long-term marginal electricity power plant technology is natural gas combined cycles (NGCC) with life cycle emissions of $376 \mathrm{~kg} \mathrm{CO}$-eq $/ \mathrm{MWh}_{\mathrm{el}}$ [47].

It is assumed that forest residues are harvested and chipped at the road side. Diesel is used as the energy source for harvesting and chipping of forest residues. The total energy requirements for harvesting and chipping of forest residues are assumed to be $3 \mathrm{kWh} / \mathrm{MWh}_{\mathrm{FR}}[37,48]$.

The LBG product is assumed to replace fossil LNG. The emissions for the liquefaction of NG are added assuming that the same type of liquefying unit as used for the LBG plant, assuming the same marginal electricity producer as in the rest of the study. A lifecycle value of emissions for NG is added based on data presented in [49], thus yielding a total GWP for fossil LNG of $261 \mathrm{~kg} \mathrm{CO}$ 2-eq $/ \mathrm{MWh}_{\mathrm{LBG}}$

Methane slip occurring during loading, unloading and fuelling of LBG is omitted in the calculations, which is in line with the assumptions in Börjesson et al.[7]. The methane slip related to incomplete combustion of methane in the engines is estimated at $0.63 \mathrm{~kg} \mathrm{CO}$-eq/MWhLBG [50]. However, as the end-use is the same in comparison with fossil LNG, it does not affect the carbon footprint. There is also a small methane slip in the LBG production process of $7.2 \cdot 10^{-6} \mathrm{~kg}$ methane/MWh biomass to the process. For all calculations where diesel is included, emissions of $0.29 \mathrm{~kg} \mathrm{CO}$-eq $/ \mathrm{kWh}_{\text {diesel }}$ are assumed.

The results for the GHG balances are presented in terms of $\mathrm{kg} \mathrm{CO}$-eq/MWhnet biomass, calculated according to Equation 2:

$$
C f=\frac{\left(\left[I_{h}+n_{t r} l_{t r} C_{t r}\right] \mathrm{FR}+\left[n_{\text {distr }} l_{\text {distr }} C_{\text {distr }}\right] \mathrm{LBG}\right) * G W P_{\text {diesel }}+\sum M \cdot G W_{\text {methane }}+\left(I_{e l}-O_{e l}\right) * G W P_{N G C C}-\mathrm{O}_{L B G} * G W P_{L N G}}{\left[I_{\text {bIP- }} I_{r s c}\right] \text { Biomass }}
$$


Cf denotes carbon footprint, I represents flows into the system and $O$ indicates a flow leaving the system, expressed in $\mathrm{MWh} / \mathrm{y} . /$ is a distance in $\mathrm{km}, n$ is the number of transportations occurring per year, $C$ is the fuel consumption in $\mathrm{kWh} / \mathrm{km}$, and $M$ is the methane slip in $\mathrm{kg} / \mathrm{y}$. The subscript $h$ denotes harvesting and tr denotes transportation of forest residues, $d$ denotes distribution of LBG, el denotes electricity, NGCC is the electricity produced in a natural gas combined cycle, bIP denotes usage in the biomass integrated process, and rsc denotes biomass usage is the reference sawmill in $M W h / y . G W P_{i}$ is the $\mathrm{CO}_{2}$ equivalents in $\mathrm{kg} \mathrm{CO}_{2}$-eq/energy unit and $G W P_{\text {methane }}$ is the global warming potential for methane in $\mathrm{kg} \mathrm{CO}$-eq $/ \mathrm{kg}_{\text {methane. }}$

\subsection{Economic performance}

The FPC is calculated per quantity of produced fuel. It is assumed that the process has an annual operating time of 8000 hours. The economic performance of the process is quantified through the fuel production cost (FPC) in Euro/MWhLBG according to Equation 3:

$$
F P C=\frac{T P I \cdot C R F+O \& M+I_{f r} P_{f r}+I_{t f r} P_{t f r}+O_{d} P_{d}+\left(I_{e l}-O_{e l}\right) P_{e l}+O_{e l} P_{e l, c e r t}-O_{w c s a w m i l l} P_{w c}+O_{B M, r e f f} P_{B M r e f}}{O_{L B G}}
$$

I represents flows into the system and $O$ indicates a flow leaving the system, expressed in $M W h / y$. O\&M denotes operation and maintenance costs. Pidenotes prices in EUR/MWh. The subscript fr stands for forest residues, $t f r$ stands for transportation of forest residues, $d$ stands for distribution of LBG, el stands for electricity, el,cert for electricity certificates (Swedish support system for renewable electricity production), sr stands for sawmill residues, wc stands for wood chips and BMref stands for biomass sold in the reference sawmill. TPI is the total plant investment cost (see Section 3.6.1) and CRF is the capital recovery factor (or annuity factor), which is set to 0.1 , which for example corresponds to an economic lifetime of 20 years and a discount rate of $8 \%$, which are typical values adopted for assessing strategic investments in industry.

\subsubsection{Investment cost data}

The investment cost of the bio-SNG plant was estimated using data gathered in a literature study of investment costs for gasification-based biofuel production compiled by Holmgren [51]. For the site power island, there is a differentiation between the cases where there is a condensing turbine stage and when there is no condensing stage. The capital cost for the power island is estimated based on data from National Energy Technology Laboratory [52]. Three different base costs are used for the reference biomass boiler, depending on size of production [53]. The boiler investment reference cost is subtracted from the investment cost of all plants, except if there is a need for a boiler at the site to sustain the heating needs of the plant.

A summary table of the investment cost data for each process unit is presented in Appendix. C Capital cost. All investment costs are in year 2015 monetary value. Adjustments have been made using the Chemical Engineering Plant Cost Index (CEPCI) [54]. For all economic calculations an exchange rate of 0.107 EUR/SEK was applied. To account for the benefits of integrating fuel production with an existing plant, investment costs for biomass handling equipment were not considered for the cases where only sawmill by-products were used as feedstock for LBG production. For cases where purchased forest residues were also used, only the new equipment needed for handling these resources were considered in the investment calculations. The investment cost for the liquefying unit was estimated based on numbers presented by Börjesson et al.[7].

\subsubsection{Energy prices}

An electricity price of 59.3 EUR/MWhel was used in the calculations. It is based on a forecast by the Swedish Energy Agency [55] for the year 2030. Renewable electricity production is assumed to be eligible for support through the Swedish electricity certificate system ${ }^{1}$. The price of electricity certificates is assumed to be 20 EUR/MWh. Consumed electricity is assumed to be purchased for the price of non-renewable electricity.

Biomass price data is based on a forecast for 2030, performed by the Swedish Energy Agency in 2014 [55], and is presented in Table 5. The prices are presented excluding transportation costs (the transportation costs vary between different cases, see Section 3.4.1). The prices of biomass are heavily dependent on season and geographical location. The lack of valid data and the uncertainty related to predicting future prices is the reason that the price of sawdust, bark and forest residues are assumed to be the same.

\footnotetext{
${ }^{1}$ Policy instrument incentive scheme promoting the production of renewable electricity, where electricity producers receive one certificate per MWh produced renewable electricity. The certificates are traded between the suppliers and consumers. A quota obligation for consumers creates a demand for the certificates and thus provides them with economic value.
} 
Table 5. Prices of biomass feedstock.

\begin{tabular}{ll} 
Type of biomass & Price [EUR/MWh] \\
\hline Sawdust & 20.3 \\
Wood chips & 23.2 \\
Bark & 20.3 \\
Biomass fuel mix & 21.7 \\
Forest residues & 20.7
\end{tabular}

\subsubsection{Transportation costs}

Transportation costs for forest residues, $P_{\text {tfr }}($ EUR/MWh) are based on Benjaminsson et al. [56] and are calculated according to Equation (4):

$$
P_{t f r}=889+30.4 * d
$$

where $d$ is the distance in $\mathrm{km}$.

For transportation of LBG the price is assumed to be $590 \mathrm{EUR} / \mathrm{MWh}$ based on data presented in Börjesson et al. [7].

\subsubsection{Sensitivity analysis}

It is natural to consider the capital cost in a sensitivity analysis, since it has a large impact on the economic performance of each case. Both feedstock price and electricity price are also included in a sensitivity analysis, since it is hard to predict future prices with accuracy, as previously mentioned. Therefore three parameters were selected for four economic sensitivity analyses:

1) Capital cost. To investigate the impact of an increased annual capital cost, the CRF was increased to 0.15 , corresponding to a higher discount rate or a shorter economic lifetime of the plant. This sensitivity analysis could also represent an increased plant investment cost.

2) Electricity price. The influence of the electricity price was assessed by increasing the electricity price by $30 \%$, thus accounting for the insecurity in predicting the price development of electricity.

3) Biomass cost decreased. There is an insecurity in predicting the demand and supply of biomass and thereby the future price of biomass, particularly low-grade biomass such as bark. Therefore, a sensitivity analysis where the purchase price of bark is set to zero is included. Even though this might be unreasonable, the demand for bark is currently often non-existent during the summer months when there is no need for heat-only boilers in the stationary energy sector. This sensitivity analysis can be viewed as an investigation of the impact of a lower feedstock price with a larger decrease of the bark price.

4) Biomass cost increased. To account for a future with high increased demand for biomass, the feedstock price is increased by $30 \%$

Since these parameters are independent of each other - within the boundaries of this study - there is no reason to vary them simultaneously.

\section{Results}

\subsection{Energy targeting}

The following sections present and discuss the results concerning the energy performance of the system. Section 4.1.1 presents the results of the energy targeting study and Section 4.1.2 presents a summary of all results. The performance results of the $250000 \mathrm{~m}^{3}$ sawmill are not presented, since they do not affect the general conclusions; and the trends are close to linear between the small and the large-scale sawmills.

\subsubsection{Process integration and energy balances}

Figure 5 shows the Grand Composite Curve (GCC) of the background process (combined LBG process and sawmill) together with the GCC of the HRSC sized to match the heat requirement of the background process. The figure illustrates Case 1 (Available sawmill residues) for the $50000 \mathrm{~m}^{3} / \mathrm{yr}$ sawmill. 


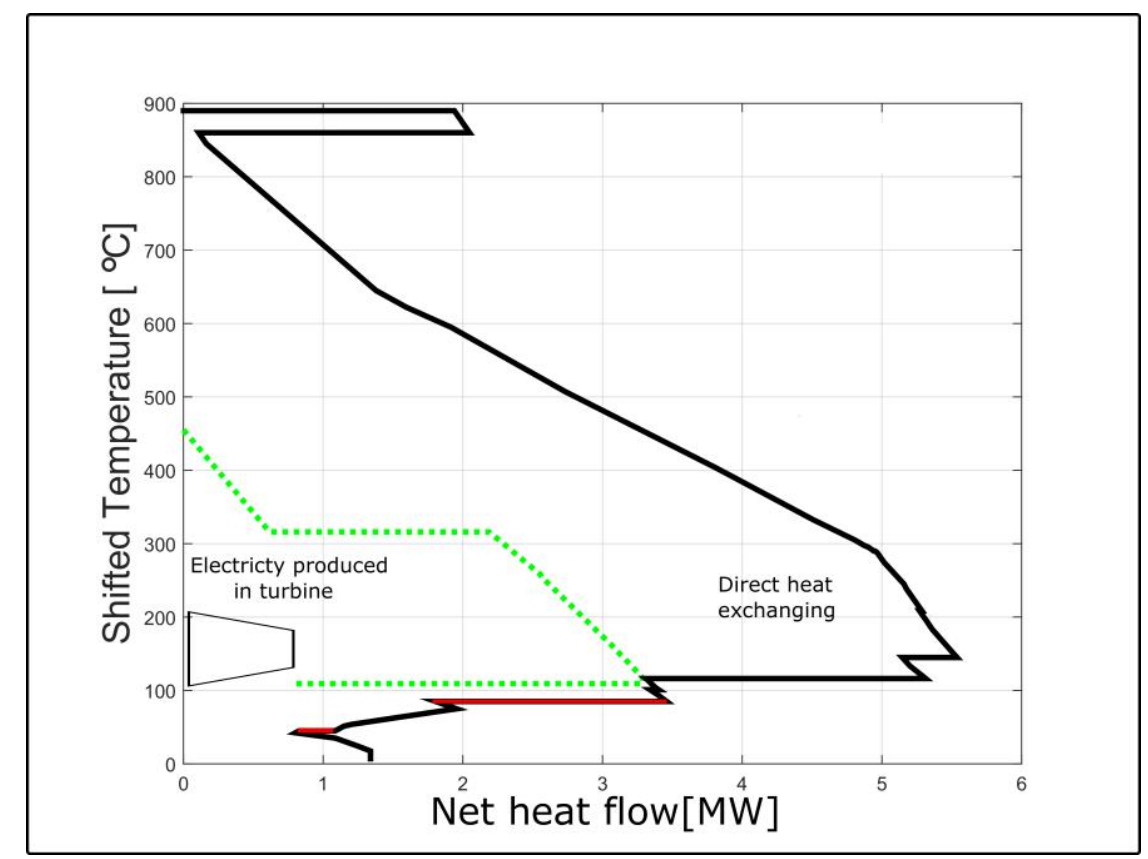

Figure 5. Case 1 for the $50000 \mathrm{~m} / \mathrm{yr}^{3}$ sawmill. The background curve of the LBG process is represented by the black line, the heat requirements of the sawmill are represented by the red lines in the background curve and the green, dotted, foreground curve is the HRSC. The steam turbine between the temperature axis and the end of the foreground curve indicates the electricity production. The area under the background curve that is not covered by the foreground curve indicates that pars of the heat integration will occur through direct heat exchanging between hot and cold streams.

By studying the curve it can be noted that there is enough excess heat from the process to cover its heating needs; the excess heat form the LBG process is sufficient to cover the heating needs of both the LBG process and the sawmill for this case. At the end of the bottom of the foreground curve, a steam turbine is included, indicating the amount of electricity that could be produced through the HRSC. However, as can be seen from the background curve, the excess heat from the integrated process is not enough to fully integrate the HRSC (dashed line), resulting in significant losses of exergy. This is because there is not enough surplus heat to raise steam with all available excess heat, and still cover the heating needs of the integrated process. This results in a scenario where as much steam as possible is produced and used for heating and electricity production through the turbine, and direct heat exchanging is used to satisfy the heating needs that are not covered with steam. 

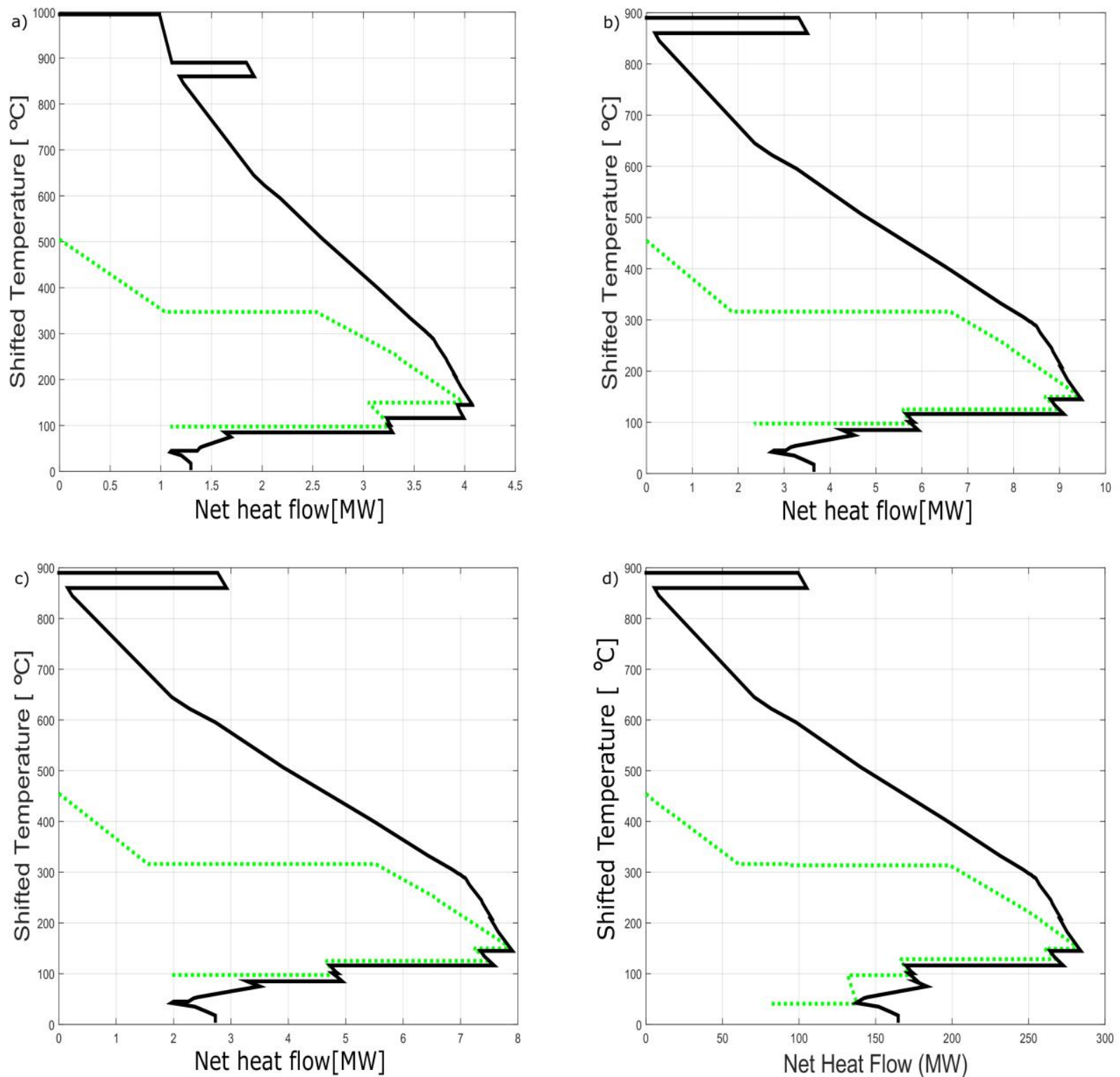

Figure 6 a), b), c), d). The foreground curve of the integrated HRSC, with the integrated sawmill-LBG process background curves of: a) Case 2 - Available sawmill residues excl. wood chips, b) Case 3 - Forest residues uptake area, note that parts of the foreground curve extends beyond the background curve, which for this case represents $L P$ steam which is ventilated after the turbine, c) Case 4-Sawmill heat demand, d) Case 5-Large scale LBG process. Note that the scale of the axes are not the same for the figures. All figures refer to the $50000 \mathrm{~m} / \mathrm{yr}^{3}$ sawmill. The reader is referred to

Figure 5, for a detailed description of the different components included in the GCC.

Figure 6 a)-d) show the foreground and background curves for the remaining four cases for the $50,000 \mathrm{~m}^{3} / \mathrm{yr}$ sawmill. The sawmill is included in the background curve as illustrated in

Figure 5 . Note that the scales of the axis are not identical for all figures. The corresponding electricity production for all cases and both sawmill sizes are presented in Table 6 .

Table 6. Electricity production [MW] for all cases.

\begin{tabular}{ccc} 
Plant size limiting factor & $\begin{array}{c}50000 \\
\mathrm{~m}^{3} / \mathrm{yr}\end{array}$ & $\begin{array}{c}500000 \\
\mathrm{~m}^{3} / \mathrm{yr}\end{array}$ \\
\hline Case 1 - Feedstock & 0.80 & 8 \\
Case 2 - Available sawmill residues & 1.1 & 10.8 \\
excl. wood chips & & \\
Case 3 - Forest residues uptake area & 2.4 & 24 \\
Case 4 - Sawmill heat demand & 2 & 20 \\
Case 5 - Large scale & 73.2 & 72.7
\end{tabular}


For Case 2 (Figure 6 a), where all available wood chips from the sawmill are exported, a fraction of the available sawmill residues are combusted in a biomass boiler that delivers the necessary heat directly to the process. The heat from the boiler is represented in the background curve. The radiative heat from the biomass boiler furnace is indicated by the horizontal line at $1000^{\circ} \mathrm{C}$ in the background curve, and the convective heat is included in the heat cascade from $1000^{\circ} \mathrm{C}$ to $150^{\circ} \mathrm{C}$. To ensure efficient use of resources, the quantity of residues combusted is such that that the HRSC can be fully integrated without involving condensing power generation. This can be observed in Figure 6 a) by noting that the foreground curve corresponding to the HRSC does not extend beyond the background curve.

Figure 6 b) shows Case 3, where $80 \%$ of the estimated available forest residues within the catchment area for the timber feedstock to the sawmill are assumed to be used as additional feedstock in the gasifier. In this case, the excess heat from the LBG process slightly exceeds the heating needs of the sawmill. This can be observed by that fact that the foreground curve extends beyond the background curve. A turbine condensing stage is required in order to produce additional electricity. However, the electricity produced in the condensing stage would be very small, and therefore a condensing stage is not included in this case, rather the remaining low pressure steam is vented to the atmosphere.

For Case 4 (Sawmill heat demand), displayed in Figure $6 \mathrm{c}$ ), it can be seen that the segments of the background curve relating to the LBG process are larger in relation to the heating need for drying in the sawmill, as compared to Case 1 (

Figure 5). As a result, the straight line at $100^{\circ} \mathrm{C}$, representing the main heating requirement at the sawmill (drying), is smaller in relation to the rest of the background curve. However, for this case the HRSC foreground curve is also fully integrated with the heat cascade of the background system - fully utilizing the excess heat that can be used in the steam cycle - and thus increasing the electricity produced in the turbine. The steam cycle is large enough to utilize all high temperature heat above the pinch to produce steam, but not larger than that it covers all the heating needs for the integrated process without any condensing power generation, as specified in the dimensioning specification for Case 4. Case 4 differs from Case 2 in that the temperature levels required to create the extra steam necessary for heating is at a higher temperature and thus more efficient from a steam cycle perspective.

Case 5, with an LBG production capacity of $500 \mathrm{MW}$, is shown in Figure $6 \mathrm{~d}$ ). For this case, the heating demands for the sawmill are significantly smaller in relation to the excess heat of the LBG process. As a large quantity of excess heat is available in this case, a condensing unit is included in the turbine. However, as lowering the pressure down to the condensing pressure $(0.1$ bar $)$ creates water drop formation in the beginning of the condensing step, a reheat step is required. The condensing stage of the power cycle can be noted as the part of the foreground curve that sticks out of the background curve at approximately $50^{\circ}$ in Figure $6 \mathrm{~d}$ ), thus changing the appearance of the background curve in relation to figures $6 \mathrm{a}$ )-c). The difference in scale becomes apparent when studying the HRSC, which for this case produces a relatively large amount of condensing electricity from the excess heat from the integrated process.

\subsubsection{Energy balances, feedstock transportation distances and total investment costs}

In Table 7 the resulting energy flows are presented for each case, together with the average transportation distance for forest residues and the total investment cost for each case. 
Table 7. Energy flows, feedstock transportation distances and total investment costs

\begin{tabular}{|c|c|c|c|c|c|c|c|c|}
\hline $\begin{array}{r}\text { Sawmill } \\
\text { size } \\
/ \text { Case }\end{array}$ & $\begin{array}{l}\text { Biomass } \\
\text { from } \\
\text { Sawmill } \\
{[\mathrm{MW}]}\end{array}$ & $\begin{array}{l}\text { Imported } \\
\text { Forest } \\
\text { residues } \\
{[\mathrm{MW}]}\end{array}$ & $\begin{array}{l}\text { Net } \\
\text { biomass } \\
\text { use [MW] }\end{array}$ & $\begin{array}{l}\text { LBG } \\
\text { produc } \\
\text { ed } \\
{[\mathrm{MW}]}\end{array}$ & $\begin{array}{l}\text { LBG } \\
\text { produced } \\
\text { per net } \\
\text { biomass } \\
\text { use }\end{array}$ & $\begin{array}{l}\text { Power } \\
\text { balance } \\
{[\mathrm{MW}]}\end{array}$ & $\begin{array}{l}\text { FR trsp. } \\
\text { distance } \\
{[\mathrm{km}]}\end{array}$ & $\begin{array}{l}\text { Invest- } \\
\text { ment } \\
\text { cost } \\
\text { [MEUR] }\end{array}$ \\
\hline
\end{tabular}

\begin{tabular}{|c|c|c|c|c|c|c|c|c|}
\hline \multicolumn{9}{|l|}{$\begin{array}{r}50000 \\
\mathrm{~m}^{3}\end{array}$} \\
\hline 1 & 14.0 & 0.0 & 11.8 & 9.7 & 0.82 & -0.7 & 0.0 & 41.2 \\
\hline 2 & 7.0 & 0.0 & 4.7 & 3.9 & 0.83 & 0.5 & 0.0 & 31.1 \\
\hline 3 & 14.0 & 10.0 & 21.8 & 16.7 & 0.77 & -0.1 & 12.9 & 72.0 \\
\hline 4 & 14.0 & 6.0 & 17.8 & 13.9 & 0.78 & -0.1 & 10.2 & 63.1 \\
\hline 5 & 14.0 & 706.1 & 717.8 & 500.0 & 0.7 & 5.9 & 110.6 & 796.0 \\
\hline \multicolumn{9}{|l|}{$\begin{array}{r}500000 \\
\mathrm{~m}^{3}\end{array}$} \\
\hline 1 & 140.4 & 0.0 & 117.9 & 97.5 & 0.82 & -7 & 0.0 & 221.6 \\
\hline 2 & 69.6 & 0.0 & 47.2 & 38.6 & 0.83 & 5.0 & 0.0 & 151.2 \\
\hline 3 & 140.4 & 99.8 & 217.7 & 166.8 & 0.77 & -1 & 40.8 & 351.2 \\
\hline 4 & 140.4 & 60.4 & 178.2 & 139.4 & 0.78 & -1 & 32.4 & 306.1 \\
\hline 5 & 140.4 & 579.7 & 697.6 & 500.0 & 0.72 & 3.7 & 100.3 & 810.3 \\
\hline
\end{tabular}

Table 7 presents the energy flows for each LBG plant sizing case. Each case has a flow of forest residues coming from the sawmill and for some of the cases, additional forest residues are imported to the process. The total biomass required is the imported biomass plus the biomass residues from the sawmill and the net biomass use is the difference in used biomass compared to the reference sawmill case. Since Cases 1 and 2 are sized according to available residues from the sawmill, no forest residues are used in these cases. For Cases 4 and 5 , the required uptake area is based on the growth rate of forest residues. For Case 3, the harvesting area for logs to the sawmill is used to calculate the collected amount of forest residues, since it is assumed that the uptake area of logs to the sawmill also provides the uptake area of additional forest residues to the LBG process. The total investment cost for each case is displayed in the last column. The power balance is the net difference between the power produced through the HRSC and the electricity used at site.

As described in Section 4.1.1, the steam cycle for Case 1 is poorly integrated, as a result of the low amount of excess heat from the LBG process in relation to the heating needs of the sawmill. This results in a negative net power balance, i.e. the electricity from the steam cycle is not sufficient to cover the electricity needs of the LBG process. However, even though the power balance is negative, the heat demand of the sawmill is satisfied relatively efficiently and no resources are used for production of condensing electricity, which results in a high production of LBG per unit of biomass used.

The export of the available wood chips in Case 2 means that there are less residues from the sawmill available as feedstock to the LBG process and parts of the available feedstock are combusted to close the energy balance of the integrated process, without need for a condensing turbine stage. This results in a case where heat is utilized as efficiently as possible and thus results in the only case where there is an excess of electricity from the process. Additionally, the net biomass use is low in relation to the amount of LBG produced.

In Case 3, the feedstock import to the process results in a surplus of excess heat, meaning that heat is to some extent used inefficiently for electricity production. This results in a relatively high net biomass use in relation to the amount of LBG produced. For Case 4, the steam cycle is by definition perfectly integrated (similar to Case 2). However, as high temperature heat from the furnace is not included, less electricity is produced, resulting in a small net electricity deficit for the process. This also results in a higher net biomass use in relation to the LBG produced for this case, as compared to Case 2.

In Case 5, the LBG process produces large amounts of excess heat that is used for electricity production through a condensing turbine stage, due to sawmill heat demand mismatch. This means that the net electricity production for this case is positive. However, the positive aspects of the process integration are limited and the energy efficiency performance is poor, with a significantly higher net biomass use in relation to the produced LBG, at the same time as a lot of excess heat is used for inefficient power generation. 
Since all flows are assumed to scale linearly when estimating the energy balances for the different cases, the dimensions of the fore- and background curves are exactly the same for all sawmill sizes, except for Case 5 . For Case 5 the size of the sawmill, relative to the LBG process, changes between the cases. The heating needs of the sawmill are lower in relation to the LBG process for the small sawmill case, and therefore the condensing turbine stage is larger for the small sawmill size compared to for the large sawmill case. Thus the electricity production per net amount of biomass differs between the sawmill sizes within Case 5; the largest electricity production is for the smallest sawmill size and the smallest electricity production is for the large sawmill, as more heat is required to dry the wood in the sawmill for that case.

\subsection{Carbon footprint}

Figure 7 presents the resulting carbon footprint, presented per net use of biomass for all cases considered, calculated as the total GHG emissions for each case, divided by the net biomass input in relation to the reference sawmill scenario. The unit is used to enable a reasonable comparison between the different cases, as the change to the system is done in relation to an assumed existing sawmill system. 


\section{GHG emissions per net biomass use}

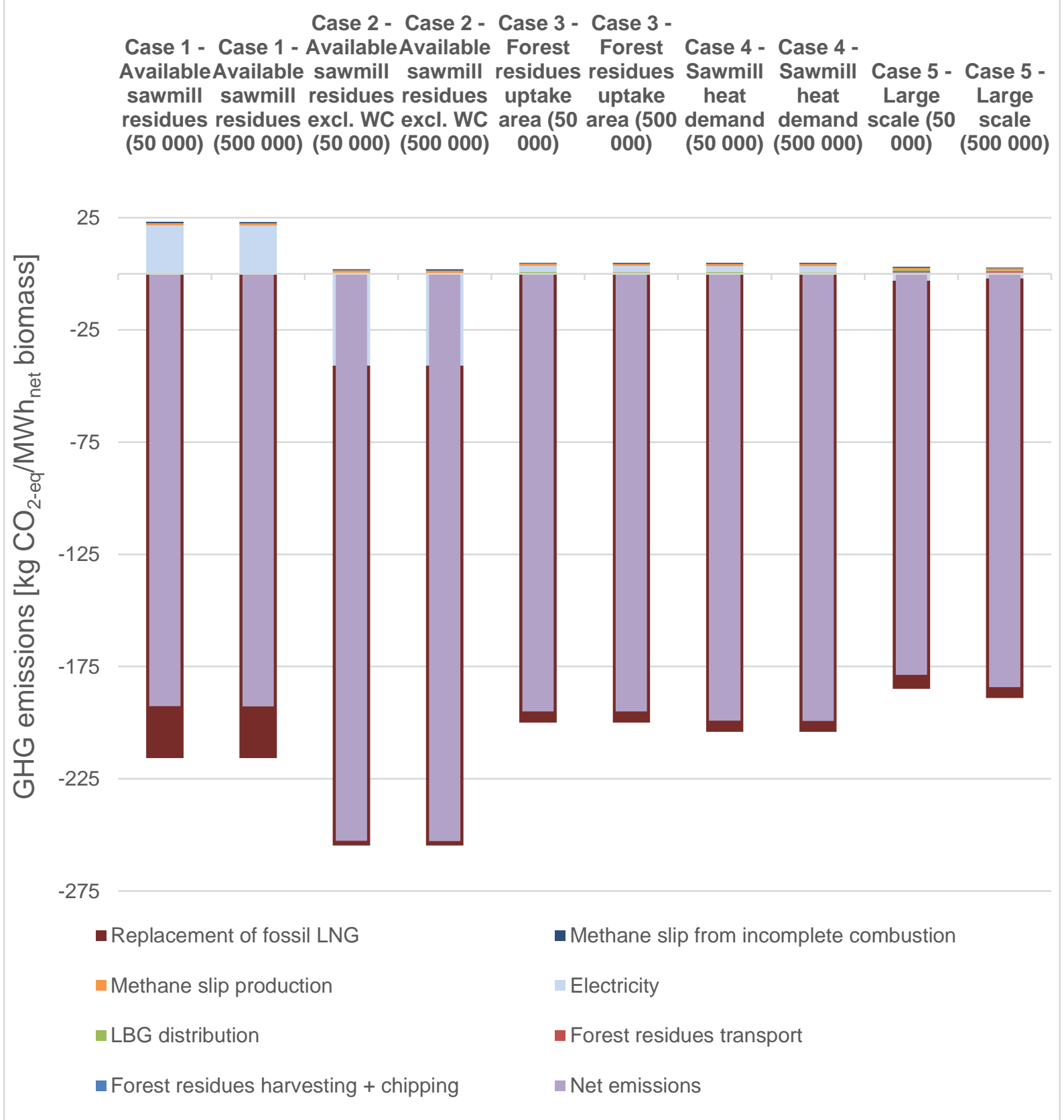

Figure 7. Resulting carbon footprint for all cases and the 50000 and $500000 \mathrm{m3} / \mathrm{yr}$ sawmill sizes. For a schematic description of the value chain, please see Figure 10.

Negative values indicate a GHG emissions reduction. The carbon footprint reduction varies between

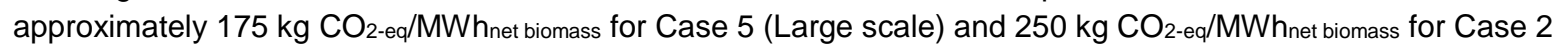
(Available sawmill residues excl. WC).

As can be seen, the replaced fossil LNG strongly offsets the emissions related to transportation, as well as the methane slips, which ultimately have a small impact on the end results in this context. This implies that the GHG balance could have been simplified, however, the sum of all small contributions makes a noticeable difference for all cases. Due to the low impact of transportation and harvesting on the carbon footprint of the entire value chain, the difference between the sawmill sizes becomes very small for all cases. 
Cases 1 and 2 produces the highest amount of LBG per net amount of biomass used (as mentioned in Section 4.1.2) and thereby have the highest replacement of fossil LNG per net biomass usage. There is a small difference between the cases, where Case 1 configurations have a somewhat larger reduction potential since a fraction of the feedstock in Case 2 is used directly for steam generation, and thereby, electricity production. However, the big difference between Cases 1 and 2 is the electricity balance. Case 2 shows a significant carbon footprint reduction potential due to replacement of marginal power production, as opposed to Case 1.

If the LBG plant is sized as in Case 2, where the woodchips are exported and some of the biomass is combusted for heat production, the best performance is achieved from a carbon footprint perspective. This highlights that it is efficient usage of excess heat at the site that is most important parameter for the carbon footprint performance. This also explains why sizing the plant according to the heating needs of the integrated sawmill/LBG process, as done in Case 4, performs second best. The difference in temperature levels between Cases 2 and 4 (see Section 4.1) which enables a better electricity balance as well as lower net biomass usage per produced amount of LBG, results in a lower carbon footprint for Case 2. The carbon footprint for Case 3 (Error! Reference source not found. c)), is slightly lower than for Case 4. This underlines that the extra feedstock to the process is not a benefit from a carbon footprint perspective since it leads to a less efficient energy system; the sawmill heat sink is not sufficiently large to accommodate all excess heat.

Case 5, with by far the largest LBG production, is shown to be inferior to all other cases regarding reduction potential of the carbon footprint. The reason is again the inefficient energy system, with significant production of condensing electricity, resulting from the severe excess heat vs. heat sink mismatch. The positive net electricity balance is not sufficient to decrease the carbon footprint noticeably. Case 5 displays a difference between sawmill sizes (see also Section 4.1.1), due to the constant size of the LBG plant regardless of sawmill sizes. Consequently, the heat mismatch is lowest when integrating with the largest sawmill, which thus results in the lowest condensing electricity production, and the least inefficient energy system.

Regardless of the sizing case, the reduction potential, as compared to the WtW emissions of fossil LNG, is significant for all considered cases, and the difference between the best and worst performing case is less than $30 \%$.

\subsection{Economic performance}

Figure 8 presents the calculated fuel production cost for all cases. "Internal feedstock" denotes the net usage of sawmill by-products that are sold in the reference sawmill case, thereby constituting a cost (or a lost revenue). The external feedstock cost is the cost for purchased forest residues. 


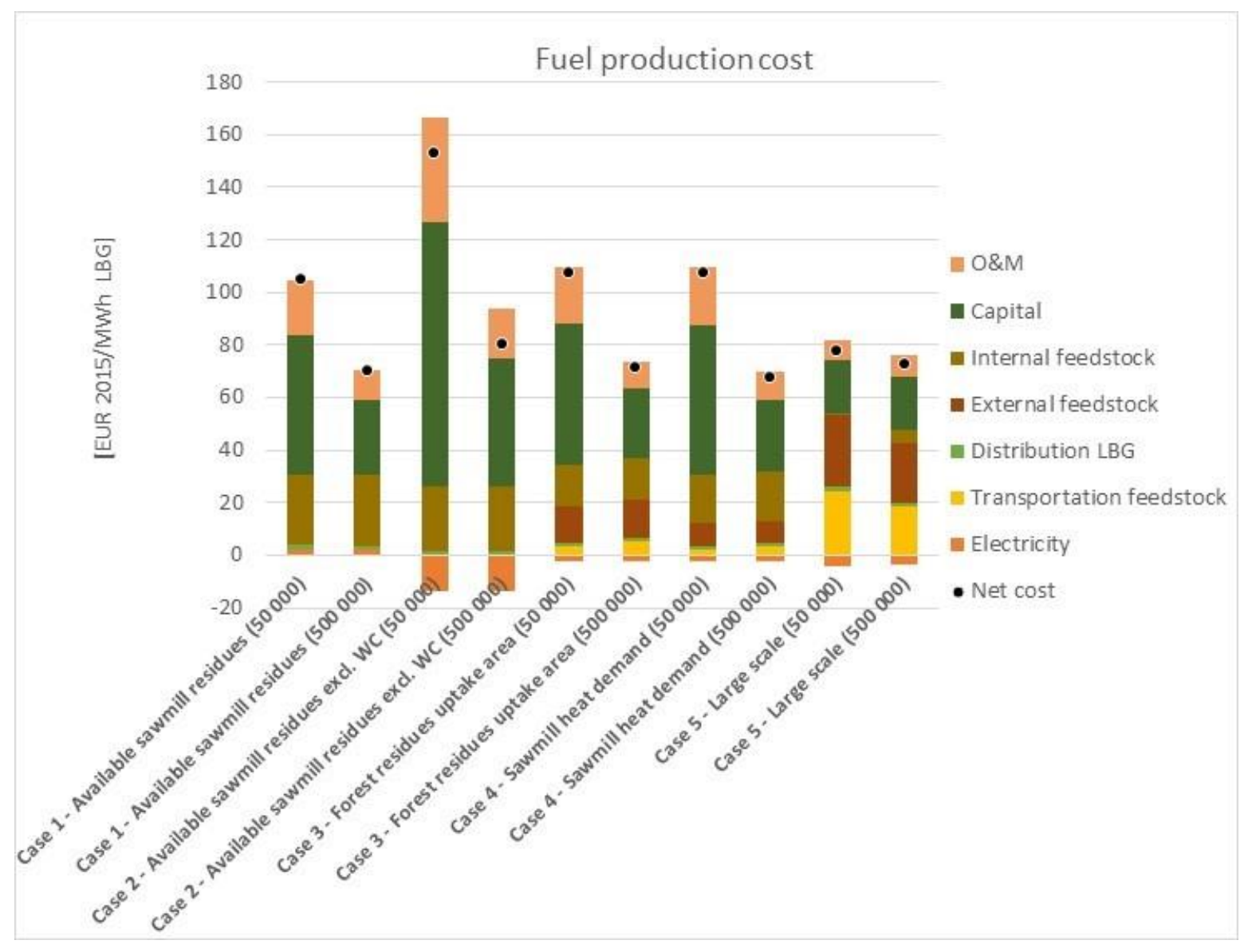

Figure 8. Fuel production cost (FPC) for all cases and the 50000 and $500000 \mathrm{m3} / \mathrm{yr}$ sawmill sizes.

The resulting fuel production cost spans over a range from 68 to 156 EUR/MWhLBG. In general, the plant costs (capital cost and O\&M) have the largest impact on the economic performance, followed by the total feedstock cost (internal or external, depending on case, plus feedstock transportation). The impact of plants costs is most significant for smaller LBG plants (Case 2 - both sawmill sizes, as well as Cases 1, 4 and 3 - small sawmills), while feedstock related costs dominate for larger plants (Case 5 - both sizes, as well as Case 3 and 4 - large mills).

Contrary to the carbon footprint results, the net electricity balance has a limited impact on the FPC. It is only for the second case that it has a more noticeable impact. The reason that some of the cases get a net revenue from electricity, even though the total power balance is negative, is that the electricity certificate revenues outweigh the net electricity purchase costs. In Sweden, all electricity produced from co-generation based on biomass is eligible for certificate revenue even if the net power balance of the plant is negative.

Contrary to the carbon footprint results, it is apparent that in economic terms, size matters. Consequently, Case 5 (Large scale) performs best in the small size sawmill, whereas for the largest sawmill, Case 4 (Sawmill heat demand) achieves the lowest FPC and both Cases 1 and 3 perform better than Case 5 . This is because the specific capital cost decreases with scale of production, which relates to the size of the sawmill for all cases except Case 5. Capital cost is not a linear function, contrary to all energy related flows, but decreases nonexponentially per produced unit with increased production (economy of scale). Thus, Cases 1-4 cannot compete for the smallest sawmill size, where the total biofuel production is several orders of magnitude higher for Case 5.

It can be noted that, similarly to the carbon footprint estimation, the net positive power production of Case 5 is not sufficient to make an offsetting difference in the total fuel production cost. For Case 5 , the LBG production and consequently the FPC are relatively unaffected by the sawmill size (Figure 8 and Table 7). The reason for decreasing FPC for Case 5 with larger sawmill size is the lowered cost for feedstock transportation due to a larger share of internal feedstock with a larger mill. The high transportation cost for the feedstock clearly limits the performance of the large scale case (Case 5), for both sizes. This is also the only case where feedstock transportation is a major contributor to the total FPC, as it constitutes about a third of the total FPC. 
While Case 2 achieves the best performance from a carbon footprint perspective, this case consistently results in the highest FPC. The reason is that the size of the LBG production is significantly lower than all other cases, which leads to a higher specific capital cost.

The lowest FPCs are found for the largest sawmill cases, and for the cases with relatively good excess heat heat load matching, i.e. Cases 4, 1 and 3, which achieve relatively similar FPCs, but with partly different cost break-downs. With similar specific capital costs, the plant costs are comparable for the three cases. The difference lies in the feedstock costs, where Case 1 has no costs for external feedstock, only lost revenue for internal feedstock, while for Case 3 and 4 feedstock transportation play an increasingly important role in the total FPC. This shows that even though Case 4 is the most efficient case from an energy point of view, the impact on the final economic result is relatively small and is overshadowed in particular by the plant costs.

In summary, the results show that capital cost has the largest impact on the FPC for all of the studied cases except Case 5, where the feedstock related costs have a larger contribution to the FPC. With increasing LBG plant sizes, feedstock costs consequently constitute an increasingly large share of the FPC.

\subsubsection{Sensitivity analysis}

Results from the economic sensitivity analysis are presented in Figure 9. Three parameters are separately varied in the analysis: the CRF to investigate the impact of increased annualized capital cost $(+)$; the cost of the feedstock (+/-); and the electricity price (+).

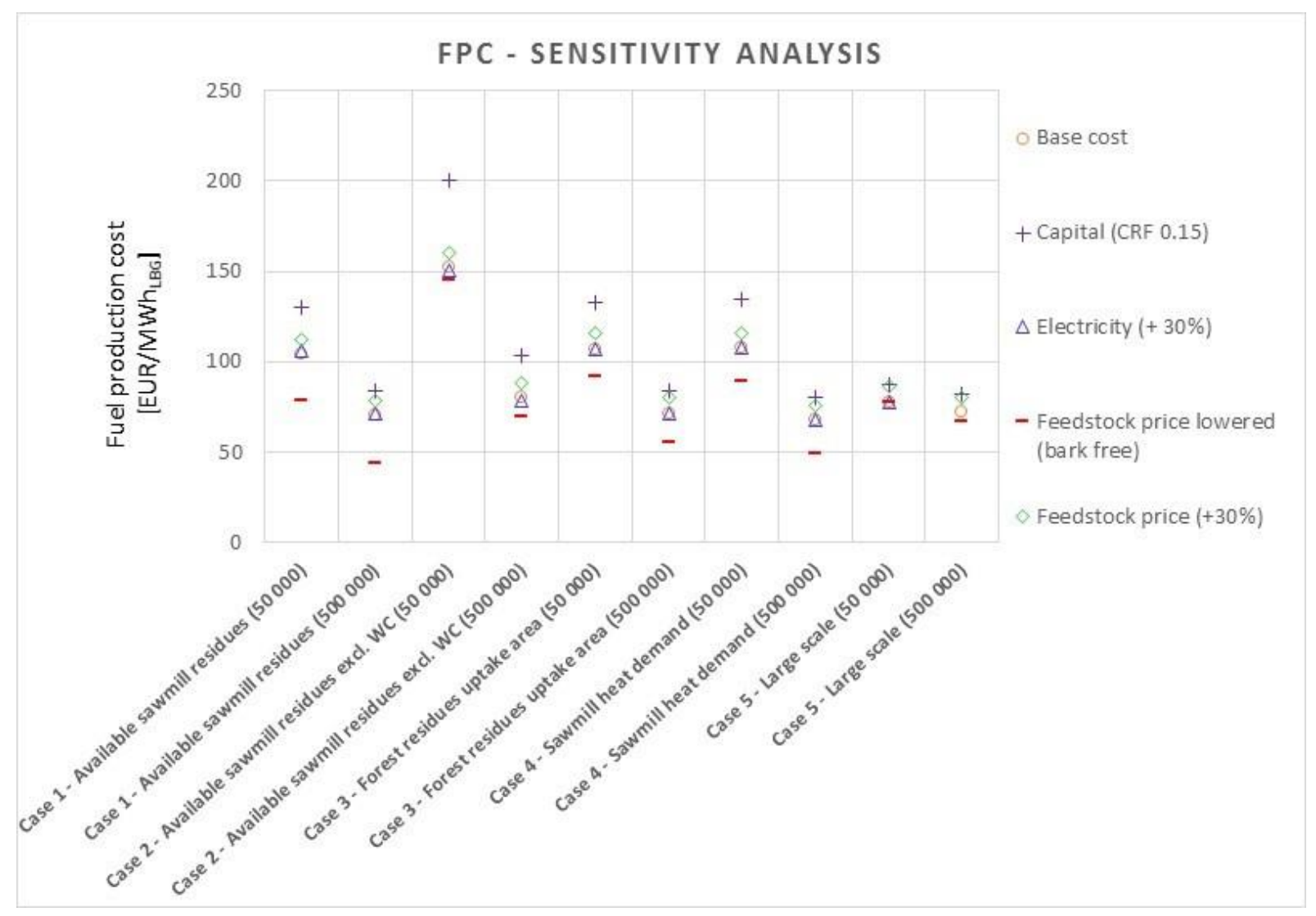

Figure 9. The influence of different parameters on the fuel production cost (FPC).

The figure shows that the trend is the same for all cases; the cost is always lowest for the $500000 \mathrm{~m}^{3} / \mathrm{yr}$ sawmill, regardless of varied parameter. As in the base case, Cases 4, 1 and 3 show similar cost performance trends. Notably, Case 1 shows the largest FPC when the sawmill bark is assumed to have no market value, since this case uses only sawmill by-products, which results in a relatively lower feedstock cost for this case. However, the difference compared to Case 4 is relatively small. Conversely, the decreased feedstock price barely affects Case 5, since the usage of internal feedstock is comparably small for that case, especially for the smallest sawmill size. Since future prices of biomass feedstock, especially bark, are uncertain and dependent on the future industrial by-product demand, those results indicate that for plants well matched to sawmill heat demands, the possibility to use internal by-products with low market value can have a significant effect on the resulting FPCs. 
When the feedstock prices are instead increased with $30 \%$, the trends follow the base results for all cases, i.e. an overall increase in feedstock price does not affect the conclusions from the study.

The increase of capital cost has a large impact on the FPC for all cases, which could be expected as it is a major contributor to the FPC. Along the same line, smaller plant sizes and sawmill cases are more affected than larger sawmills or cases (in particular Case 5), due to the larger relative contribution to the FPC for the smaller plants. This serves to further emphasise the importance of economies of scale.

An increase of electricity price has a limited impact on all the studied cases, which emphasizes that the electricity production will have only a minor impact on the profitability of the plant. The only case where the difference becomes discernible is for Case 2 where the relative electricity production per net amount of biomass is, by far, the largest.

The relative consistency of the trends between the four different sensitivity analyses indicates that the conclusions which can be drawn from the results are robust.

\section{Discussion}

In terms of carbon footprint, it is apparent that the energy efficiency of the biofuel production site and how efficiently excess heat is cascaded through the HRSC have the largest impact on the results. This influences the electricity production, as well as the LBG production, per net biomass usage for the site. This suggests that the most important measure to lower the carbon footprint of the process is to integrate the HRSC as much as possible, avoiding condensing electric power generation and without importing any feedstock in addition to that provided by the background host process. That Case 2 performs the best in terms of carbon footprint is explained by the smaller net amount of biomass required to fully integrate the HRSC when part of the biomass is combusted. That efficient use of excess heat is the key factor to lower the carbon footprint is also stressed by the relatively poorer performance of Case 5 , which has the smallest benefits of process integration due to the significant heat mismatch between the sawmill and LBG process.

The only case with a net electricity production is also the case that has the lowest carbon footprint. However, if the assumed emissions associated with external electricity production were changed to e.g. the emission levels representative of the Swedish electricity mix or wind power, the results would shift. Case 1 would perform best, followed by Case 2. This clearly highlights that since the other aspects of the value chain have such a limited impact on the carbon footprint; for a future where emissions related to electricity production are small or very small, it is mainly the net use of biomass in relation to the LBG production that affects the carbon footprint of the process.

Regarding the economic performance, it is obvious that the scale of production has a major impact on the performance. However, since the specific capital cost decreases with increasing size, at a certain point the increasing cost of transporting the additional required feedstock to the plant will outweigh the benefits of a larger plant. Heat integration also has a significant impact on the economic performance. Compared to for the carbon footprint, the feedstock integration perspective is more important here. When the biofuel process requires substantially more feedstock than can be provided by the sawmill, the influence of feedstock transportation becomes apparent. Case 4 for the largest sawmill size achieves the lowest FPC, with Cases 1 and 3 only about $3 \%$ behind. All these cases have relatively low transportation costs. The relative performance of the different cases remains the same for all sensitivity analyses, except if the bark feedstock is assumed to be available for free. This indicates that the results and conclusions are relatively robust.

The results of the analysis show clearly that process integration is an important aspect when producing LBG integrated with a sawmill. If the biofuel process is too large in relation to the sawmill, the possibilities of extracting heat are limited, which means that the process performs poorly from a carbon footprint perspective, at the same time as the FPC becomes higher than it needs to be due to high transportation costs for feedstock. Consequently, it is not reasonable to make a process that sells all available wood chips for additional income - even if it leads to high energy efficiency and a low carbon footprint - since the penalty resulting from less opportunities for process integration leads to high FPC. Instead, the case performing best from an economic perspective is Case 4 for the largest sawmill size, where enough feedstock is imported to fully integrate the HRSC with the background process. For the medium and small sawmill sizes, the same conclusions can be drawn from a carbon footprint emission perspective. However, when looking at the economic performance, the economy of scale is lost for the small sawmill size, where it is instead Case 5 that performs best, as economies of scale are inherent to this case.

\section{Conclusions}

The aim of this study was to investigate the impact from different parts of the value chain for LBG production integrated with a generic Nordic sawmill, in terms of carbon footprint and fuel production cost. Five different sizing criteria for the LBG production plant in relation to three different sawmill sizes were evaluated, applying a 
perspective concerning the entire value chain from well-to-tank for the economic performance and well-to-wheel for the carbon footprint calculations.

The results show that regardless of the assumed sizing criterion for the LBG plant, the reduction potential of the carbon footprint from gasification based LBG production is significant, with essentially negligible emissions from most parts of the value chain compared to the offset emissions from replacing fossil LNG. The reduction potential varies between 175 and $250 \mathrm{~kg} \mathrm{CO}_{2 e q}$ per net use of biomass, accounting for the difference in biomass use compared to a reference stand-alone sawmill scenario. The net electricity production causes the largest variation. Large LBG plants in, on relative terms, small sawmills were shown to result in heat mismatch and inefficient energy systems with condensing electricity production, resulting in lower carbon footprint reduction potential.

Regarding fuel production cost, the results indicate a significantly larger variation: from 68 to 156 EUR per MWh LBG. This is due to scale effects, with smaller plants or integration with smaller sawmills suffering from high specific capital and O\&M costs, thus leading to higher fuel production costs. If considering only the largest sawmill cases, the production cost range is considerably lower: 68-82 EUR per MWh LBG, which can be compared to an average Swedish price of natural gas for industrial users of 34 EUR/MWh 2015 [57].

In summary, the results from this study show that the energy performance of the production process has the largest impact on the value chain performance in terms of carbon footprint, while the size of the production plant has the largest impact on the fuel production cost, followed by feedstock transportation costs for larger plants. It can be concluded that there are clear gains to be obtained by integrating gasification-based LBG production $t$ at sawmill sites, and that the gains increase with the size of the sawmill. Regarding suitable sizing criteria, a close match between excess heat from the LBG plant compared to the available heat sink of the sawmill leads to the best overall performance. This can be achieved in different ways, with similar performance identified when using all available by-products from the mill as feedstock (including the wood chips), or when supplying additional feedstock in the form of forest residues, up to a level equal to $80 \%$ of the available logging residues from the supply area of timber to the mill.

It is clear that process integration of an indirect gasifier for LBG production is an effective way for a sawmill to utilize its by-products, still covering its heating needs but allowing for an extension of its product portfolio in a competitive way, both from a carbon footprint and cost perspective. However, small scale sawmills would suffer from high investment costs in relation to the quantity of fuel produced, which means that the incentives for major investments in LBG production through gasification are lacking, even though the environmental gains are clear in terms of carbon footprint. For larger scale sawmills, however, the results show that production costs can be competitive and, furthermore, the importance of process integration is clearly underlined. The cases where the sizing of the LBG process in relation to the sawmill where performed well from an integration perspective (cases 1. 3. \& 4.) achieves equal or lower LBG production costs than the large scale case (Case 5.).

These results provide insights about which value chain parameters are of the most important to consider when sizing the LBG process in relation to an existing sawmill. They also visualize how the carbon footprint can be significantly decreased by integrating production gasification facilities at existing industrial sites, for a type fuel for which an increasing demand is already seen. Furthermore, it provides important guidelines and incentives for sawmill industries on how to make investments in renewable fuel production.

\section{Acknowledgements}

The work was carried out under the auspices of Forskarskola Energisystem financed by the Swedish Energy Agency. Economic support from the Swedish Research Council FORMAS is also gratefully acknowledged (dnr. 213-2014-184). 


\section{References}

1. SOU, Fossil Freedom on the road. Part 2 [Fossilfrihet på väg. Del 2. SOU 2013:84]. Stockholm,. 2013.

2. Gröbl, T., H. Walter, and M. Haider, Biomass steam gasification for production of SNG - Process design and sensitivity analysis. Applied Energy, 2012. 97: p. 451-461.

3. Gassner, M. and F. Maréchal, Thermo-economic optimisation of the polygeneration of synthetic natural gas (SNG), power and heat from lignocellulosic biomass by gasification and methanation. Energy and Environmental Science, 2012. 5(2): p. 5768-5789.

4. Alamia, A., et al., Well-to-wheel analysis of bio-methane via gasification, in heavy duty engines within the transport sector of the European Union. Applied Energy, 2016. 170: p. 445-454.

5. Alamia, A., et al., Performance of large-scale biomass gasifiers in a biorefinery, a state-of-theart reference. International Journal of Energy Research, 2017: p. DOI: 10.1002/er.3758.

6. Pettersson, K., et al., Integration of next-generation biofuel production in the Swedish forest industry - A geographically explicit approach. Applied Energy, 2015. 154: p. 317-332.

7. Börjesson, P., et al., Methane as vehicle fuel - a well-to-wheel analysis $\mathrm{f} 3$ The Swedish Knowledge Centre for Renewable Transportation Fuels and Foundation, Sweden. Available at www.f3centere.se, 2016(Report No 2016:06,).

8. Börjesson, P., et al., Dagens och framtidens hållbara biodrivmedel. f3 The Swedish Knowledge Centre for Renewable Transportation Fuels and Foundation, Sweden. Available at www.f3centere.se, 2013. 13(Report No 2013:13).

9. Ekbom, T., H. Gåverud, and B. Rehnlund, E.ON Gasification Development AB, Marknadsförutsättningar för biodrivmedel. 2012.

10. Calderón, A.J., P. Agnolucci, and L.G. Papageorgiou, An optimisation framework for the strategic design of synthetic natural gas (BioSNG) supply chains. Applied Energy, 2017. 187: p. 929-955.

11. Heyne, S., H. Thunman, and S. Harvey, Extending existing combined heat and power plants for synthetic natural gas production. International Journal of Energy Research, 2012. 36(5): p. 670681.

12. Andersson, J., J. Lundgren, and M. Marklund, Methanol production via pressurized entrained flow biomass gasification - Techno-economic comparison of integrated vs. stand-alone production. Biomass and Bioenergy, 2014. 64: p. 256-268.

13. Aziz, M., et al., Integration of energy-efficient empty fruit bunch drying with gasification/combined cycle systems. Applied Energy, 2015. 139: p. 188-195.

14. Lim, W., K. Choi, and I. Moon, Current status and perspectives of Liquefied Natural Gas (LNG) plant design. Industrial and Engineering Chemistry Research, 2013. 52(9): p. 3065-3088.

15. Kumar, S., et al., LNG: An eco-friendly cryogenic fuel for sustainable development. Applied Energy, 2011. 88(12): p. 4264-4273.

16. The Danish Maritime Authority, North European LNG Infrastructure Project. Available from http://www.Ingbunkering.org/sites/default/files/2012\%20DMA\%20North\%20European\%20LNG \%20Infrastructure\%20Project 0.pdf, 2012.

17. LNG Blue Corridors. 2017 [cited 2017 6/26]; Available from: http://lngbc.eu/.

18. Isaksson J, J.M., Åsblad A, Berntsson T, Transportation fuel production from gasified biomass integrated with a pulp and paper mill: - Part A: Heat integration and system performance. Energy, 2015.

19. Ljungstedt, H., K. Pettersson, and S. Harvey, Evaluation of opportunities for heat integration of biomass-based Fischer-Tropsch crude production at Scandinavian kraft pulp and paper mill sites. Energy, 2013. 62: p. 349-361.

20. Mesfun, S., et al., Integrated SNG production in a typical Nordic sawmill. Energies, 2016. 9(5).

21. Anderson, J.O. and A. Toffolo, Improving energy efficiency of sawmill industrial sites by integration with pellet and CHP plants. Applied Energy, 2013. 111: p. 791-800.

22. Lindholm, E.-L., et al., Greenhouse gas balance of harvesting stumps and logging residues for energy in Sweden. Scandinavian Journal of Forest Research, 2011. 26(6): p. 586-594.

23. Hammar, T., et al., Time-Dynamic Effects on the Global Temperature When Harvesting Logging Residues for Bioenergy. BioEnergy Research, 2015. 8(4): p. 1912-1924.

24. Holmgren, K.M., et al., Comparison of integration options for gasification-based biofuel production systems - Economic and greenhouse gas emission implications. Energy, 2016. 111: p. $272-294$. 
25. Delin, L., et al., FRAM Final report-Application area: Model mills and system analysis. Stockholm, Sweden: STFI-Packforsk, 2005.

26. Corder, S.E., Properties and uses of bark as an energy source. 1976, Corvallis, Or.: Forest Research Laboratory, Oregon State University.

27. Heyne, S., Bio-SNG from Thermal Gasification-Process Synthesis, Integration and Performance. 2013: Chalmers University of Technology.

28. Wadsborn, R., N. Berglin, and T. Richards, Konvertering av mesaugnar från olje-till biobränsleeldning-drifterfarenheter och modellering. Värmeforsk, Stockholm, 2007.

29. Seemann, M., Personal interview, J. Ahlström, Editor. 2016.

30. Alamia, A., H. Thunman, and M. Seemann, Process Simulation of Dual Fluidized Bed Gasifiers Using Experimental Data. Energy and Fuels, 2016. 30(5): p. 4017-4033.

31. Heyne, S. and S. Harvey. Production of synthetic natural gas from biomass-process integrated drying. in 22nd International Conference on Efficiency, Cost, Optimization, Simulation and Environmental Impact of Energy Systems. 2009.

32. Heyne, S. and S. Harvey, Impact of choice of CO2 separation technology on thermo-economic performance of Bio-SNG production processes. International Journal of Energy Research, 2014. 38(3): p. 299-318.

33. Birgen, C. and S. Garcia Jarque, Liquefied Synthetic Natural Gas from Woody biomass Invetigation of Cryogenic Technique for Gas Upgrading. 2013, Chalmers University of Technology.

34. Bauer, F., et al., Biogas upgrading-Review of commercial technologies. SGC Rapport, 2013.

35. Kemp, I.C., Pinch analysis and process integration: a user guide on process integration for the efficient use of energy. 2011: Butterworth-Heinemann.

36. Morandin, M., et al., Synthesis and parameter optimization of a combined sugar and ethanol production process integrated with a CHP system. Energy, 2011. 36(6): p. 3675-3690.

37. Wetterlund, E., et al., Optimal localisation of next generation biofuel production in Sweden. $\mathrm{f} 3$ The Swedish Knowledge Centre for Renewable Transportation Fuels and Foundation, Sweden. Available at www.f3centere.se, 2013(Report No 2013:8).

38. de Jong, J., et al., Realizing the energy potential of forest biomass in Sweden-How much is environmentally sustainable? Forest Ecology and Management, 2017. 383: p. 3-16.

39. Leduc, S., Development of an optimization model for the location of biofuel production plants. 2009: Citeseer.

40. Anheden, M., et al., Value chains for production of renewable transportation fuels using intermediates. $\mathrm{f} 3$ The Swedish Knowledge Centre for Renewable Transportation Fuels and Foundation, Sweden. Available at www.f3centere.se, 2016. Report No 2016:05.

41. Graz, T., et al., The Handook of Emission Factors for Road Transport 3.1. 2010.

42. Gas Infrastructure Europe. LNG map. 2015 [cited 2016 2016-07-07]; Available from: http://www.gie.eu/index.php/maps-data/lng-map.

43. Swedish Forest Industries Federation. Member compainies and products. 2014 [cited 2016 08/07/16]; Available from: http://www.forestindustries.se/about-us/member-map.

44. Christiansen, L., Skogsstatistisk årsbok 2014. Skogsstyrelsen, Skogsstyrelsen, 2014.

45. Benjaminsson, J. and R. Nilsson, Distributionsformer för biogas och naturgas i Sverige. Rapport på uppdrag av Energigas Sverige, Grontmij, 2009.

46. Change, I.C., The physical science basis. Contribution of working group I to the fifth assessment report of the intergovernmental panel on climate change. K., Tignor, M., Allen, SK, Boschung, J., Nauels, A., Xia, Y., Bex, V., Midgley, PM, Eds, 2013: p. 1535.

47. Axelsson, E., S. Harvey, and T. Berntsson, $A$ tool for creating energy market scenarios for evaluation of investments in energy intensive industry. Energy, 2009. 34(12): p. 2069-2074.

48. Eliasson, L., et al., Analyses of single-grip harvester productivity. Journal of Forest Engineering, 1999. vol.10 no.1.

49. Axelsson, E. and K. Pettersson, Energy price and Carbon Balances Scenarios tool (ENPAC)a summary of recent updates. 2014, Chalmers University of Technology.

50. Gode, J., et al., Miljöfaktaboken 2011-estimated emission factors for fuels, electricity, heat and transport in Sweden. Värmeforsk, Stockholm, 2011.

51. Holmgren, K., Investment cost estimates for biomass gasification based systems. IVL Swedish Environmental Research Institute, IVL B-report B, 2015. 2221.

52. Fout, T., et al., Cost and performance baseline for fossil energy plants. Volume 1a: Bituminous coal (PC) and natural gas to electricity. Revision 3. 2015, DOE/NETL-2015/1723. Pittsburgh, PA, USA: National Energy Technology Laboratory. 
53. Goop, J., District heating in the Nordic countries-modelling development of present systems to 2050. Chalmers University of Technology, available at http://www.lib.chalmers.se/, 2012.

54. Bailey, M.P., Chemical engineering plant cost index (cepci). Chemical Engineering, 2014. 121(2): p. 68-69.

55. The Swedish Energy Agency, Scenarier över Sveriges energisystem. Energimyndigheten, 2014. ER 2014:19.

56. Benjaminsson, G., J. Benjaminsson, and N. Bengtsson, Decentraliserad produktion av pyrolysolja för transport till storskaliga kraftvärmeverk och förgasningsanläggningar. Swedish., Gasefuels AB, 2013.

57. The European Commission. eurostat Statistics explained Energy price statistics. 2016 [cited 17 02/15]; Available from: http://ec.europa.eu/eurostat/statisticsexplained/index.php/Energy price statistics.

58. Preem, Klimatprestanda för Preems drivmedelsprodukter. Preem.se, 2014.

59. Swedish Forest Industries Federation. Member compainies and products. 2014; Available from: http://www.forestindustries.se/about-us/member-map.

60. Heyne, S., H. Thunman, and S. Harvey, Exergy-based comparison of indirect and direct biomass gasification technologies within the framework of bio-SNG production. Biomass Conversion and Biorefinery, 2013. 3(4): p. 337-352.

61. Heyne, S., M.C. Seemann, and S. Harvey, Integration study for alternative methanation technologies for the production of synthetic natural gas from gasified biomass, in Chemical Engineering Transactions. 2010. p. 409-414.

62. Götz, M., et al., Potential to optimize scrubbers for biogas cleaning part 2. Chemical scrubbers. Chemie-Ingenieur-Technik, 2012. 84(1-2): p. 81-87.

63. Grabke, H. and M. Spiegel, Occurrence of metal dusting-referring to failure cases. Materials and corrosion, 2003. 54(10): p. 799-804.

64. Arvidsson, M., M. Morandin, and S. Harvey, Biomass gasification-based syngas production for a conventional oxo synthesis plant - Greenhouse gas emission balances and economic evaluation. Journal of Cleaner Production, 2015. 99: p. 192-205.

65. Liu, G., et al., Making Fischer-Tropsch fuels and electricity from coal and biomass: Performance and cost analysis. Energy and Fuels, 2011. 25(1): p. 415-437.

66. Hannula, I. and E. Kurkela, Liquid transportation fuels via large-scale fluidised-bed gasification of lignocellulosic biomass. 2013. 


\section{Appendix A. Transportation calculations}

\section{Transport and distribution}

\section{Forest residues}

To account for the energy demand for transportation of branches and tops to the process site, data from [44] and [37] are used to estimate the growth rate of wood per unit area in Sweden [37] in 2030 (average for the entire country). The uptake area for each case is calculated according to:

$$
A=\frac{1}{k} * \frac{Q_{\text {Import }} * t_{\text {ap }}}{G_{\text {forest residues }} / p * A_{\text {Sweden }}{ }^{-1}}
$$

where, $A$ is the uptake area in hectares, QImport, is the required import of forest residues to the process (MW),

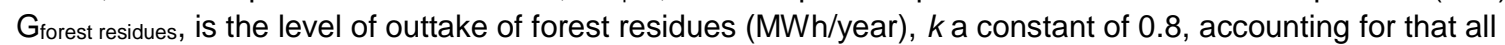
feedstock within an area cannot be expected to be used by one single actor, $p$ is a constant of 1.2 , used as an estimation of the forest density within areas where sawmills are located, compared to average forest land, and $t_{a p}$ denotes production hours per year.

Forest and harvesting data are presented in Table 8, all data is for Sweden year 2030. The forest data used represents a scenario that assumes a future with forest management practices where high productivity is prioritized.

Table 8. Forest data. Conversion factor odt $/ \mathrm{m}^{3}$ wood Conversion factor MWh/odt 4.9 Annual growth rate of branches, roots and tops TWh/y Total area Sweden hectare

0.42
4.9
34780.200
23200000

The chipped forest residues are assumed to be transported by truck to the sawmill-integrated LBG process. The trucks are assumed to run on Sulphur-free MK1 diesel mixed with $5 \%$ bio diesel (RME). The capacity of the trucks can be limited either by volume or mass, and the limits for the forest residues trucks are specified to 25 metric tons and $115 \mathrm{~m}^{3}$. With a density of forest residues of 0.29 metric tons $/ \mathrm{m}^{3}$ volume is consequently the limiting aspect of transportation [56]. The related GHG emissions could then be calculated in terms of $\mathrm{CO}_{2}$ equivalents using the WTW GHG emissions for the fuel [58].

\section{LBG distribution}

Data for the sawmills, their location and capacities is mainly taken from [59] and verified with [44]. The mapping of sawmills and LNG terminals is displayed in Figure 10. The circles around the LNG terminals have a diameter of $200 \mathrm{~km}$ and are included to visualize the spatial coverage of LNG terminals within a reasonable distance from Swedish sawmills. 


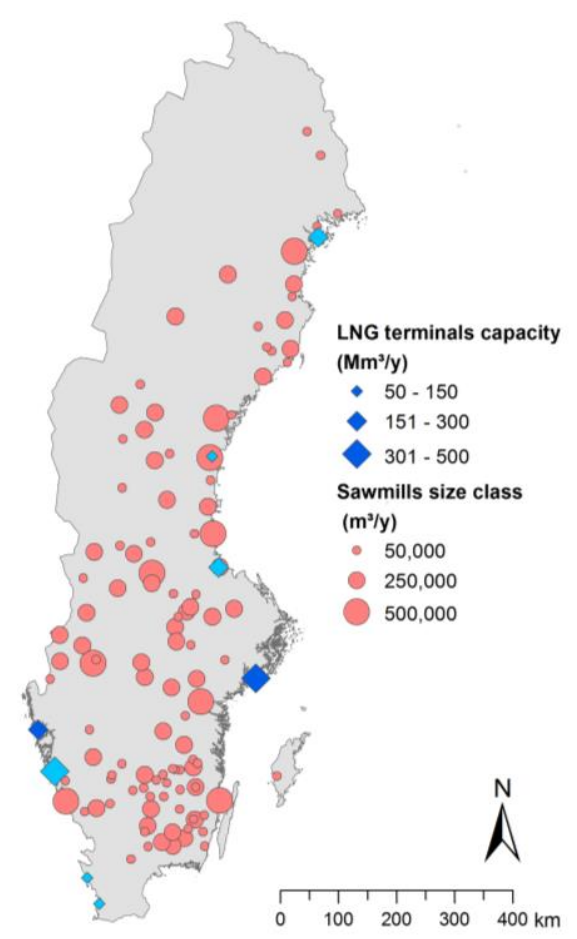

Figure 10. Mapping of sawmills and existing (dark blue) and potential new (light blue) LNG terminals in Sweden. Sawmills have been categorized in three size classes, as described in the text

As can be noted in Figure 10, the annual LNG handling capacity varies between the terminals. Theoretically this means that some of the terminals would not be able to handle all of the produced LBG for the cases with large LBG production size and would thereby be forced to deliver LBG to more than one terminal. However, a close examination of the map indicates that even if transportation to two or more LBG terminals would be necessary, the distance would not increase significantly for most locations, except the most remote locations. Therefore, the average distance from each sawmill size to the nearest LBG terminal is used for calculations.

The transportation capacity for each LBG truck is specified to 25 metric tons, based on a web-based search of companies selling trailers used for LNG transportation with heavy trucks. The fuel consumption of the trucks was specified to $0.4 \mathrm{l} / \mathrm{km}[7,45]$.

\section{Appendix. B Process and process simulation assumptions}

A general presentation of modelling assumptions are presented here. However, since the data is based on modelling performed by Heyne [27], the reader is referred there for a thorough review of all modelling assumptions and process layout justifications.

The air dryer is modelled using a specific energy demand of $2600 \mathrm{KJ}$ of heat per $\mathrm{kg}$ of water and dries the biomass from $50 \%$ wt to $20 \% \mathrm{wt}$. The indirect gasifier is modelled using a simplified stoichiometric model, accounting for solely five species, $\mathrm{H}_{2}, \mathrm{CH}_{4}, \mathrm{CO}_{2}, \mathrm{CO}$ and $\mathrm{H}_{2} \mathrm{O}$. For a detailed description of the reaction scheme see Heyne et al. [60].

The adiabatic fixed bed methanation sections are based on Haldor Topsøe technology and are modelled using a Gibbs equilibrium reactor in Aspen Plus, with a stoichiometric amount of steam added to keep a $\mathrm{H}_{2} / \mathrm{CO}$ ratio of 3 , via water-gas-shift reaction. For a more thorough review of how the methanation was modelled, see Heyne et al [61]. An MEA scrubber is used for the $\mathrm{CO}_{2}$ removal. It is modelled assuming a $\mathrm{CO}_{2}$ separation efficiency of 0.9965 and a methane slip of 0.0005 . The separation process is thoroughly described in Heyne and Harvey [32], their model is mainly based on data from a previous study by Götz et al [62].

The reversed Bryton cycle, used to liquefy the bio-SNG to LBG was modelled by Garcia and Birgen, with assistance by Heyne [33]. The liquefaction occurs at a pressure of 40 bars and the LBG is cooled using nitrogen. The cooling procedure occurs in several steps for a closer match of the cooling gradient curve of the methane and the heating gradient curve of the nitrogen, thereby keeping the temperature difference between the streams small. Calculator blocks were used in Aspen plus to control the pressure after the expanders to keep the temperature difference between the streams close to $2^{\circ} \mathrm{C}$. 
Oversizing the gasification process to produce electricity through a HRSC is not efficient from a thermodynamic point of view, the HRSC is rather used to make use of excess heat as efficiently as possible. The temperature and pressure of the HRSC steam system extraction points were specified so as to maximize the electricity production of the steam cycle. The assumed isentropic efficiencies of the turbine and pump are 0.78 and 0.8 , respectively [36].

The HRSC is subject to a corrosive environment and therefore the maximum temperature of the HRSC is limited to $450^{\circ} \mathrm{C}$ for a pressure of 100 bar to avoid metal dusting, as recommended by Grabke and Spiegel [63]

\section{Appendix. C Capital costs}

The plant capital costs were estimated using the data gathered in the literature report by Holmgren (2015) [51]. All base data, scaling parameters and costs are presented in The BOP includes the additional direct costs and accounts for site preparation, equipment erection, piping, instrumentation and controls, electricity, utilities, offsites, buildings (including services). For the cases where the BOP is not applied, these costs are already included in the base cost.

Table 9. However, for a thorough review of all assumptions and references for the data, the reader is referred to the report. The BOP (balance of plant) which is used in some of the cases, is - if not otherwise noted determined through equation (6)

$$
B O P(\%)=\frac{0.8867}{{\text { Biomass } M W_{H H V}}^{0.2085}}
$$

The BOP includes the additional direct costs and accounts for site preparation, equipment erection, piping, instrumentation and controls, electricity, utilities, off-sites, buildings (including services). For the cases where the BOP is not applied, these costs are already included in the base cost.

Table 9. Investment cost data

\begin{tabular}{|c|c|c|c|c|c|c|c|c|c|c|}
\hline & $\begin{array}{l}\text { Base } \\
\text { size } \\
\text { cost }\end{array}$ & $\begin{array}{c}\text { Cost unit } \\
\text { Currency \& } \\
\text { base year }\end{array}$ & $\begin{array}{l}\text { Scaling } \\
\text { factor }\end{array}$ & $\begin{array}{l}\text { Base } \\
\text { scale }\end{array}$ & $\begin{array}{c}\text { Scaling } \\
\text { parameter } \\
\text { unit }\end{array}$ & $\begin{array}{l}\text { Max. } \\
\text { size }\end{array}$ & $\begin{array}{l}\text { Lower } \\
\text { size }\end{array}$ & $\begin{array}{c}\text { BOP cost (\%) } \\
\text { (Sometimes } \\
\text { installation } \\
\text { factor instead) }\end{array}$ & $\begin{array}{l}\text { Indirect } \\
\text { costs (\%) }\end{array}$ & $\begin{array}{l}\text { Working } \\
\text { capital \% }\end{array}$ \\
\hline $\begin{array}{l}\text { Biomass } \\
\text { receive and } \\
\text { unload }\end{array}$ & 3.5 & M\$ 2007 & 0.62 & 198.1 & \multicolumn{2}{|c|}{$\begin{array}{l}\text { tonne wet biomass } \\
\text { input/h }\end{array}$} & - & 0.155 & 0.32 & 0.05 \\
\hline $\begin{array}{l}\text { Biomass } \\
\text { storage. } \\
\text { Preparation. } \\
\text { feeding }\end{array}$ & 2 & M\$ 1999 & 0.77 & 64.6 & $\begin{array}{l}\text { Biomass } \\
\text { feed. }\end{array}$ & 110 & - & $\begin{array}{l}\text { See equation } \\
(6)\end{array}$ & 0.32 & 0.05 \\
\hline $\begin{array}{c}\text { Biomass air } \\
\text { dryer }\end{array}$ & 0.7 & MSEK 2003 & 0.8 & $\begin{array}{c}122183 \\
2\end{array}$ & \multicolumn{3}{|c|}{$\begin{array}{c}\text { volumetric flow rate of hot } \\
\text { drying air }\end{array}$} & included & 0.32 & 0.05 \\
\hline $\begin{array}{l}\text { Biomass air } \\
\text { drying }\end{array}$ & 0.7 & MSEK 2003 & 0.8 & $\begin{array}{c}122183 \\
2\end{array}$ & \multicolumn{3}{|c|}{$\begin{array}{c}\text { volumetric flow rate of hot } \\
\text { drying air }\end{array}$} & $\begin{array}{l}\text { According to } \\
\text { [32] }\end{array}$ & Included & - \\
\hline $\begin{array}{c}\text { Indirect } \\
\text { gasifier + } \\
\text { combustor }\end{array}$ & 14 & SEK 2003 & 0.72 & 158.7 & $\begin{array}{l}\text { MWth } \\
\text { input }\end{array}$ & 200 & - & 3.72 & 2.6 & - \\
\hline Tar reformer & 2 & $M € 2012$ & 0.6 & 1717.1 & \multicolumn{2}{|c|}{ syngas flow in mol/s } & - & 4.862 & 3.41 & \\
\hline Tar reformer & 93.7 & M\$ 2007 & 0.9 & 31000 & \multicolumn{2}{|c|}{$\begin{array}{l}\text { syngas flow at exit } \\
\mathrm{kmol} / \mathrm{hr}\end{array}$} & - & Included & Included & 0.05 \\
\hline Fabric filter & 79.1 & $k € 2012$ & 0.7 & 15.6 & $\mathrm{~m} 3 / \mathrm{s}$ & 470 & - & 4.488 & 4.11 & 0.05 \\
\hline $\begin{array}{l}\text { Water } \\
\text { scrubber }\end{array}$ & 3 & M\$ 2002 & 0.7 & 12.1 & $\mathrm{~m} 3 / \mathrm{s}$ & 64 & - & 0.231 & 0.5 & 0.1 \\
\hline $\begin{array}{l}\text { MEA/ CO2 } \\
\text { removal } \\
\text { island }\end{array}$ & 4.7 & $M € 2010$ & 0.6 & 3.6 & $\begin{array}{c}\text { kg CO2 } \\
\text { separated } \\
\text { per second }\end{array}$ & - & - & $\begin{array}{l}\text { According to } \\
{[32]}\end{array}$ & Included & - \\
\hline $\begin{array}{l}\text { Hydrogen } \\
\text { membrane } \\
\text { (MEA) }\end{array}$ & 500 & $\$ 2006$ & 1 & 420 & $\begin{array}{l}\text { number of } \\
\text { sheets }\end{array}$ & - & - & $\begin{array}{l}\text { According to } \\
\text { [32] }\end{array}$ & Included & - \\
\hline $\begin{array}{l}\text { Gas drying } \\
\text { unit (MEA) }\end{array}$ & 73.4 & $k € 2010$ & 0.7 & 7000 & - & - & - & $\begin{array}{l}\text { According to } \\
{[32]}\end{array}$ & Included & \\
\hline
\end{tabular}




\begin{tabular}{|c|c|c|c|c|c|c|c|c|c|c|}
\hline $\begin{array}{l}\text { Methanation } \\
\text { island } \\
\text { adiabatic } \\
\text { methanation. }\end{array}$ & 4381 & $k € 2007$ & 0.7 & 175 & $\begin{array}{l}\text { MW HHV } \\
\text { SNG }\end{array}$ & - & - & $\begin{array}{l}\text { According to } \\
{[64]}\end{array}$ & Included & - \\
\hline $\begin{array}{l}\text { methanation } \\
\text { island } \\
\text { catalyst }\end{array}$ & 845 & $k € 2012$ & 0.7 & 175 & $\begin{array}{l}\text { MW HHV } \\
\text { SNG }\end{array}$ & & & $\begin{array}{l}\text { According to } \\
{[64]}\end{array}$ & Included & - \\
\hline $\begin{array}{c}\text { Syngas } \\
\text { compressor \& } \\
\text { recycle } \\
\text { compressor } \\
\text { methanation }\end{array}$ & 6.31 & $k € 2012$ & 0.67 & 10 & MWe & - & 70 & Included & 0.32 & 0.05 \\
\hline $\begin{array}{l}\text { Zinkbed } \\
\text { guard bed }\end{array}$ & 0.78 & M\$ 2007 & 0.67 & 2020 & $\begin{array}{l}\text { MW HHV } \\
\text { SNG }\end{array}$ & - & - & $\begin{array}{c}\text { According to } \\
{[64]}\end{array}$ & Included & - \\
\hline $\begin{array}{l}\text { Zinkbed } \\
\text { guard bed } \\
\text { Sorbent }\end{array}$ & 2 & M\$ 2007 & 0.67 & 2020 & $\begin{array}{l}\text { MW HHV } \\
\text { SNG }\end{array}$ & - & - & $\begin{array}{c}\text { According to } \\
{[64]}\end{array}$ & Included & - \\
\hline Flash tank & 13 & $k € 2010$ & 0.67 & 8.6 & m3 & 520 & & $\begin{array}{c}\text { According to } \\
{[64]}\end{array}$ & Included & - \\
\hline TSA-Drying & 74 & 2010 & 0.67 & 20.7 & $\begin{array}{l}\mathrm{kg} / \mathrm{h} \mathrm{H} 2 \mathrm{O} \\
\text { adsorbed }\end{array}$ & - & - & $\begin{array}{l}\text { According to } \\
{[64]}\end{array}$ & Included & - \\
\hline $\begin{array}{l}\text { TSA-Drying } \\
\text { adsorbent }\end{array}$ & 42.4 & 2010 & 0.67 & 20.7 & $\begin{array}{l}\mathrm{kg} / \mathrm{h} \mathrm{H} 2 \mathrm{O} \\
\text { adsorbed }\end{array}$ & - & - & $\begin{array}{l}\text { According to } \\
{[64]}\end{array}$ & Included & - \\
\hline $\begin{array}{l}\text { Steam cycle } \\
\text { (turbine. } \\
\text { piping. } \\
\text { auxiliaries) }\end{array}$ & 66.7 & M\$ 2007 & 0.67 & 275 & $\begin{array}{c}\text { ST gross } \\
\text { power } \\
\text { production. } \\
\text { MWe }\end{array}$ & 293 & - & 0.155 & Included & 0.05 \\
\hline $\begin{array}{l}\text { Boiler/steam } \\
\text { generator/du } \\
\text { ctwork/stack }\end{array}$ & 52 & M\$ 2007 & 1 & 355 & $\begin{array}{l}\text { Boiler duty } \\
\text { MWth }\end{array}$ & 355 & - & $\begin{array}{l}\text { See equation } \\
(6)\end{array}$ & 0.27 & 0.05 \\
\hline $\begin{array}{l}\text { Steam cycle } \\
\text { (turbine, } \\
\text { piping, } \\
\text { auxiliaries) }\end{array}$ & 66.7 & M\$ 2007 & 0.67 & 275 & $\begin{array}{l}\text { ST gross } \\
\text { power } \\
\text { production. } \\
\text { MWe }\end{array}$ & 293 & - & 0.155 & Included & 0.05 \\
\hline $\begin{array}{c}\text { Condensing } \\
\text { unit }\end{array}$ & 11 & M\$ 2007 & 0.67 & 553 & MWe & - & - & $\begin{array}{l}0.155 \text { According } \\
\text { to }[65] \&[52]\end{array}$ & Included & 0.05 \\
\hline $\begin{array}{l}\text { Heat only } \\
\text { boiler small }\end{array}$ & 60.2 & MSEK 2012 & 0.7 & 7 & MW fuel & 10 & & - & Included & - \\
\hline $\begin{array}{l}\text { Heat only } \\
\text { boiler } \\
\text { medium }\end{array}$ & 136 & MSEK 2012 & 0.7 & 17 & MW fuel & 20 & 10 & - & Included & - \\
\hline $\begin{array}{l}\text { Heat only } \\
\text { boiler large }\end{array}$ & 219 & MSEK 2012 & 0.7 & 30 & MW fuel & - & 20 & - & Included & - \\
\hline $\begin{array}{c}\text { Liquefaction } \\
\text { unit }\end{array}$ & 80 & MSEK 2015 & 0.6 & 100 & GWh LBG & - & - & - & Included & - \\
\hline
\end{tabular}

The total cost of the production unit was calculated as the average value of the lowest possible and the highest possible investment cost, accounting for all necessary process equipment. In general the component costs have to be complemented by adding the indirect cost. The indirect costs include costs for engineering, contingency start-up and head office. If the indirect cost is noted to be included, these costs are already accounted for in the base cost. All values and comparisons are based on costs and performances of $N_{\text {th }}$ plants, meaning that it is assumed that the technology have been implemented in commercial scale.

Different cost data from different studies for all parts of the gasification unit are calculated and scaled to the correct size using Equation (7)

$$
C=C_{0} * \frac{s}{}^{k}
$$

$C$ is the calculated cost for the equipment, $C_{0}$ is the base cost for the equipment, $S$ is the scale of the equipment and $S_{0}$ is the reference scale, $k$ is the individual cost scaling exponent. For the equipment parts where 
a maximum size is given, e.g. the indirect gasifier, there is a need for several similar equipment parts. For those cases a scaling exponent of 0.9 , described as the train cost, $C_{m}$, is used, according to Equation (8)

$$
C_{m}=C * n^{m}
$$

$n$ is the number of required units, $C$ is the cost for each unit and $m$ is the scaling exponent accounting for total cost reduction when several similar equipment units are installed. For the cases where more than one unit is required, the load was assumed to be distributed equally between the units. For the cases where the required scale of the production unit is within $5 \%$ larger than what is specified as maximum size, the scale is rounded to one unit less, i.e. the equipment scale is allowed to be $5 \%$ larger than maximum. The O\&M cost for the process is based on [66] and is specified to $4 \%$ of the total plant cost. 